\title{
El caso de la Cantina. Un escándalo palaciego en el Madrid de Carlos II
}

\author{
Arturo ECHAVARREN \\ Consejo Superior de Investigaciones Científicas \\ Centro de Ciencias Humanas y Sociales \\ arturoechavarren@hotmail.com
}

Recibido: 18 de octubre de 2013

Aceptado: 9 de octubre de 2014

\section{RESUMEN}

Este artículo examina las intrigas de Nicole Quentin, conocida en España como la Cantina, dueña de retrete de la reina María Luisa de Orleans, primera esposa de Carlos II. Con el concurso de fuentes contemporáneas, se examinan las rivalidades palaciegas y las motivaciones políticas que condujeron a la instrucción de un proceso criminal contra la Cantina en julio de 1685, que concluyó con la expulsión de toda la servidumbre francesa de la casa de la reina.

Palabras clave: Cantina, María Luisa de Orleans, motín francófobo, Carlos II.

\section{The Case of "la Cantina". A Palace Scandal in the Madrid of Charles II}

\begin{abstract}
This paper casts light on the intrigues of Nicole Quentin, known in Spain as "la Cantina", a French dueña de retrete to the Queen Marie Louise of Orléans, first wife of Charles II of Spain. Drawing on a wealth of contemporary documents, this article examines the palace rivalries and political scheming which led the dueña to be subjected to a criminal process, concluding with the exile of all the French servants to the Queen.
\end{abstract}

Key words: Cantina, Queen Marie Louise of Orleans, Gallophobic Revolt, Charles II of Spain. 


\section{INTRODUCCIÓN}

El primer lustro de los dos que reinó en España María Luisa de Orleans, sobrina de Luis XIV, estuvo marcado por las intrigas de una dama francesa conocida como la Cantina, que culminaron en uno de los motines francófobos más virulentos que estallaron en Madrid en el reinado de Carlos II. A pesar de su importancia, no se ha prestado atención monográfica a este señalado episodio histórico. La exposición moderna más completa de sus principales hitos se encuentra en la monografía acerca de María Luisa de Orleans que el Duque de Maura compuso en los años cuarenta del siglo pasado. A pesar de su indudable valor documental, en lo tocante al caso de la Cantina la obra contiene numerosas omisiones y abunda en errores ${ }^{1}$. Heredan estos errores, claro está, quienes acuden a Maura para elaborar un epítome de las actividades de la dama francesa ${ }^{2}$.

Con el fin de arrojar nueva luz sobre aquellos sucesos históricos, se hace necesaria una revisión por menudo de los textos contemporáneos. El más importante de ellos es el auto del proceso criminal contra la Cantina, redactado por el licenciado Francisco Bravo de Sobremonte el 2 de agosto de 1685 y conservado manuscrito en la Biblioteca Nacional. En este documento de exquisita minuciosidad se consignan las diligencias del caso y las declaraciones de todas las personas implicadas en el proceso que llevó al destierro a la Cantina y su camarilla ${ }^{3}$. Se hace también imprescindible la consulta de una carta anónima redactada poco después del 30 de julio de 1685, conservada igualmente en la Biblioteca Nacional, que principalmente da cuenta del desenlace del episodio ${ }^{4}$. La correspondencia del Duque de Montalto con Pedro Ronquillo, embajador de Carlos II en Londres, ofrece una vívida estampa de las actividades de la Cantina previas al proceso y también esclarece detalles sobre su destino

1 Maura, G.: María Luisa de Orleans, reina de España. Leyenda e historia, Madrid, Saturnino Calleja, s. a., pp. 131 y 145. Entre los errores más notables se encuentra la identificación del juez Francisco Bravo de Sobremonte, encargado de instruir el caso contra la Cantina, con su padre, el médico Gaspar Bravo de Sobremonte, o la llamativa confusión de Valencia con Cuenca, ciudad esta última donde, como veremos, fueron prendidos los denunciantes de la Cantina. Maura llevó a cabo un primer acercamiento, muy escueto, al episodio palaciego en su monografía sobre el último de los Austrias. Véase MAURA, G.: Vida y reinado de Carlos II, Madrid, Aguilar, 1990, pp. 305-306.

2 Véase por ejemplo NadA, J.: Carlos II el Hechizado, trad. M. T. Gispert, Barcelona, Caralt, 1968, pp. 143 y 146, que incurre en los mismos errores que Maura, a saber, la confusión entre Francisco Bravo de Sobremonte y su padre y entre Cuenca y Valencia. Notables errores contiene también la relación del episodio en Bennassar, B.: Reinas y princesas del Renacimiento a la Ilustración. El lecho, el poder y la muerte, Barcelona, Paidós, 2007, pp. 108-109, que yerra al señalar que el marido de la Cantina se batió en duelo en Madrid con Pedro Levillane, cosa que el primero hizo en la ciudad de Limburgo con un caballero francés; al indicar que Margarita Lautier trabajaba en las caballerizas de la reina, siendo en realidad clavecinista; al escribir que el Conde de Oropesa era marqués y al suponer, en fin, que el apellido de soltera de la Cantina era "du Serroy" y no "Duperroy". En el indispensable manual sobre el reinado del último de los Austrias compuesto por Kamen, el episodio de la Cantina se resume en una sola frase: "En 1685 parece que se acusó a la reina de haber abortado un posible hijo" (KAmen, H.: La España de Carlos II, trad. J. M. Barnadas, Barcelona, Crítica, 1981, p. 587). Por último, aunque contiene numerosas vaguedades y omisiones, parece carecer de errores de bulto la relación del episodio en Pfandu, L.: Carlos II, trad. de M. Fernández Galiano, Madrid, Afrodisio Aguado, 1967, pp. 236-240.

3 Biblioteca Nacional de España (BNE), Ms. 18755/19.

4 BNE, Ms. 11017, ff. 221r-223v. 
último ${ }^{5}$. Es igualmente crucial la correspondencia de dos diplomáticos extranjeros en Madrid, Sebastiano Foscarini ${ }^{6}$, embajador de la serenísima república de Venecia desde 1682 hasta 1686, y Koenraad van Heemskerk ${ }^{7}$, embajador de Holanda desde 1680 hasta 1686. Por último, son también de gran utilidad dos cartas de agosto de 1685 escritas por Rodrigo Fernández Zorrilla y dirigidas al Duque de Gandía, donde se proporcionan detalles sobre la conclusión del episodio ${ }^{8}$.

El suceso, que de haber ocurrido unos años antes no hubiera pasado de ser un tema de comadreo burlón en las gradas de San Felipe o en los patios del Álcázar Real, debió su singular desarrollo y violento desenlace a su desarrollo en el marco de las tensas relaciones que mantenían Francia y España en la década de los años 80 del siglo XVII ${ }^{9}$; a partir de la Paz de Nimega, firmada el 11 de agosto de 1678 entre Francia y Holanda, a la que se vino a sumar España el 17 de septiembre de ese mismo año, se sucedió en Europa una etapa que bien puede describirse como guerra fría, en la que Francia expandió sus fronteras mediante la llamada Política de Reuniones. La corona francesa se acogía a una interpretación abusiva del derecho feudal alemán, según el cual era lícito atribuir al señor de una plaza fuerte, ciudad o señorío la soberanía sobre cuantas propiedades hubieran estado vinculadas feudalmente a dicho territorio. Luis XIV ordenó establecer con presteza Cámaras de Reuniones en Metz, Breisach y Besançon, que se volcaron denodadamente en la búsqueda e intervención de todos los territorios que hubieran dependido en alguna ocasión de aquellos que Francia había adquirido en los tratados de Münster y Nimega ${ }^{10}$. Aunque Suecia, Austria y la ciudad libre de Estrasburgo se vieron afectadas por numerosas anexiones en plena paz, fue España la más perjudicada por los designios de las Cámaras de Reuniones. Después de solicitar en vano amparo a los poderes europeos, Carlos II no tuvo más remedio que declarar la guerra a Francia el 11 de diciembre de $1683^{11}$. Dada la desastrosa indefensión militar de los territorios ultrapirenaicos, la guerra fue tan breve

5 Montalto, Duque de: Cartas del Duque de Montalto a D. Pedro Ronquillo, embajador de S.M.C. en Inglaterra, desde 3 de enero de 1685 hasta 30 de diciembre de 1688, en Colección de Documentos Inéditos para la Historia de España (CODOIN), Madrid, Miguel Ginesta, t. LXXIX, 1882, pp. 299-475.

6 Archivio di Stato di Venezia (ASVE), Senato, Dispacci degli ambasciatori, Spagna, C. 121 y 123 (sin foliación).

7 Cito la carta de Heemskerk, despachada el 2 de agosto de 1685 y recibida el día 28 del mismo mes, por la copia conservada en Archives du Ministère des Affaires Etrangères de France (AMAE), Correspondance Politique, Espagne, t. LXIX, ff. 235r-244v.

8 Archivo Histórico Nacional (AHN), Nobleza, Osuna, CT. 47, D. 9 (1 de agosto de 1685) y D. 10 (8 de agosto de 1685).

9 Para el seguimiento de esta crisis, véase Boutant, Ch.: L'Europe au grand tournant des années 1680, París, 1985. También es muy estimable el estudio de SALVAdor Esteban, E.: "La quiebra de la hegemonía hispánica en Europa. Un proceso complejo", en ArAnda PÉRez, F. J. (ed.): La declinación de la monarquía hispánica en el siglo XVII, Cuenca, Ediciones de la Universidad de Castilla-La Mancha, 2004, pp. 221-248, y la excelente monografía de Bernardo Ares, J. M.: Luis XIV rey de España: de los imperios plurinacionales a los estados unitarios (1665-1714), Madrid, Iustel, 2008. Para la relación hispano-gala durante el reinado del último de los Austrias, véase el reciente estudio de Maquart, M.-F.: L'Espagne de Charles II et la France 1665-1700, Toulouse, Presses Universitaires du Mirail, 2000, que emplea abundante documentación francesa inédita.

10 Voltaire, en alusión a esta política, afirmaba con orgullo que “depuis Charlemagne on n'avait vu aucun prince agir ainsi en maître et en juge des souverains, et conquérir des pays par des arrêts" (VolTAIRE: Le siècle de Louis XIV, ed. P. du Chesne de Ciszeville, París, Lehuby, 1847, p. 150).

11 La declaración de guerra se entendió en su momento como un desesperado intento de salvar "siquiera la reputación de las armas contra la murmuración, no en todo injusta, de que sin más demostración que palabras 
como virulenta, en la que se sucedieron bombardeos implacables a las poblaciones de Luxemburgo y Oudenaarde. El 15 de agosto de 1684 se firmó la Paz de Ratisbona, que ratificaba una tregua de veinte años, según la cual el Cristianísimo retenía los territorios ocupados mediante la Política de Reuniones, por lo que España perdía la provincia de Luxemburgo y los últimos eslabones del famoso "pasillo de los españoles". Aunque el tratado supuso la ratificación implícita de la supremacía de Francia en Europa, tuvo, no obstante, la virtud de conglomerar la oposición contra la corona francesa, pues la arbitrariedad del Rey Cristianísimo puso en guardia a casi todas las monarquías europeas. La desatención de Luis XIV en 1683 a la petición de auxilio emitida por el emperador de Austria a todos los príncipes de la cristiandad para que le ayudaran a liberar Viena del asedio turco y el alevoso bombardeo de Génova en mayo de 1684 contribuyeron a aumentar el sentimiento galófobo por toda Europa. En Madrid, donde el termómetro de la galofobia era especialmente sensible a los acontecimientos políticos, la desolación y amargura producida por la Política de Reuniones y la tregua de Ratisbona, entendida como una claudicación indecorosa, encontraron en la persona de la Cantina un cauce fortuito para la vindicación nacional.

La situación interna del reino en tiempo del estallido de la crisis de la Cantina también influyó notablemente en su evolución. En abril de 1685 se produjo un hondísimo desconcierto en la corte tras la dimisión como primer ministro del Duque de Medinaceli, debida principalmente a las secuelas de la hemiplejia que arrastraba desde 1683, al fracaso de su política exterior, al feroz hostigamiento de las facciones cortesanas contrarias a su modus gubernandi y, sobre todo, a su notoria incompatibilidad con la reina María Luisa ${ }^{12}$. A partir del 2 de junio de 1685, el poder fue asumido de facto por el joven Conde de Oropesa, emparentado con la Casa de Braganza, que había sido nombrado presidente del Consejo de Castilla en junio de 1684, apoyado por la reina madre, la reina reinante y un amplio sector de la aristocracia, desengañada del gobierno anterior ${ }^{13}$. No obstante, por fina prudencia cortesana, Oropesa no procuró para sí el nombramiento de primer ministro, con el fin de suavizar los escrúpulos del rey en torno a la figura de valido y de sortear los embites de los detractores del modelo de privanza, que se habían multiplicado durante el ministerio del Duque de Medinace$\mathrm{li}^{14}$. Pese a las innegables ventajas políticas de esta medida, la renuncia del Conde a

y quejas se dejasen tanto tiempo expuestos aquellos vasallos a tan horrible plaga" (Idea y proceder de Francia desde las paces de Nimega hasta la primavera del año mdclxxxiv, Barcelona, s.i., s.a., p. 41).

12 Sobre las consecuencias de la hemiplejia, véase la carta que el Conde de La Vauguyon despacha a Luis XIV el 8 de julio de 1683 (AMAE, Correspondance Politique, Espagne, t. LXVIII, f. 412r).

13 Para un acercamiento al gobierno de Oropesa, véase Bernardo Ares, J. M. de: "El Conde de Oropesa. El antifranquismo como causa de un proceso político", en MuÑoz MACHADO, S. (ed.): Los grandes procesos de la historia de España, Barcelona, Crítica, 2002, pp. 172-192.

14 Sebastiano Foscarini comenta del modo siguiente la estrategia del Conde de Oropesa: "Ha egli sfuggito di assumere il titolo, guardando altrettanto gelosamente quello di Presidente di Castiglia, per esser il vero che preserva il re dai scrupoli della privanza. Cosi all'incontro procura di avvalorare il supposto della sua autorità con equivoco di procedere artificiosissimo, onde può dirsi dell'enigma del suo elevamento o privanza, che, tanto nel principio come nel mezzo della sua durazione, è un misto d'implicanze" (BARozzi, N. y Berchet, G. [eds.]: Relazioni degli stati europei lette al Senato dagli ambasciatori veneti nel secolo decimosettimo. Serie I. Spagna, Venecia, P. Naratovich, 1860, t. II, p. 518). Muchos miembros de la alta aristocracia, descontentos con la práctica gubernamental del Duque de Medinaceli, creían fundado su derecho a participar en la política del reino más allá de acatar las resoluciones que aquel tomaba. Como alternativa al sistema de privanza y su deri- 
ser nombrado formalmente primer ministro de Carlos II llevó a la palestra el debate, alimentado por las redes clientelares de Medinaceli, acerca de la legitimidad de su gobierno. La crisis de la Cantina, que afloró tan solo un mes después de su asunción del timón de la monarquía, significó para Oropesa una oportunidad insospechada para hacer alarde de su poder ante la corte y ahogar los ánimos de los opositores en aquellos delicados momentos de transición gubernamental. La utilización política del escándalo palatino abortó, como veremos, toda resolución pacífica del conflicto.

\section{LOS INTRIGANTES}

La Cantina, como la conocían los españoles, tenía por nombre Nicole Duperroy. Había nacido en París en torno al año $1644^{15}$. Al contraer matrimonio con Jean Quentin, cirujano de Felipe de Orleans, hermano menor de Luis XIV, pasó a llamarse Nicole Quentin. El Duque de Orleans, casado con Enriqueta de Inglaterra, hija del rey Carlos I, nombró a Nicole Quentin nodriza de su hija María Luisa, que vio la luz el día 27 de marzo de 1662. El vínculo que en aquellos años se forjó entre Nicole Quentin y la princesa fue muy estrecho, especialmente tras el fallecimiento de Enriqueta cuando María Luisa contaba ocho años de edad.

Con el correr de los años, como feliz consecuencia de la Paz de Nimega, el 30 de agosto de 1679 se firmaba el compromiso matrimonial entre la sobrina de Luis XIV y el rey Carlos II, al día siguiente se celebraba la boda por poderes en Fontainebleau y el 20 de septiembre de ese mismo año María Luisa de Orleans emprendía el viaje para España. En el formidable séquito que acompañaba a la princesa se encontraba Nicole Quentin, viuda ya del cirujano del Duque de Orleans, en calidad de azafata o dueña de retrete ${ }^{16}$. El empleo no era en modo alguno trivial; las dueñas de retrete, que rendían cuentas directamente a la camarera mayor, tenían a su cuidado las llaves de la cámara y la antecámara de la reina, por lo que controlaban el tránsito por aquellas áreas íntimas del palacio ${ }^{17}$.

vación en ministeriado, una parte de esta facción crítica defendía un modelo de gobierno en el que el monarca dirigiera en persona el timón del reino, aunque con el consenso de los Grandes de España, cuyos pareceres se expresarían en el Consejo Real. Véase Carrasco Martínez, A.: «El príncipe deliberante abstracto. Debate político en torno al rey y la monarquía de España (1680-1700)», en RiBot, L.: Carlos II. El rey en su entorno cortesano, Madrid, Centro de Estudios Europa Hispánica, 2009, pp. 81-107.

15 BNE, Ms. 18755/19.

16 Véase LÉOnARdon, H.: "Relation du voyage fait en 1679 au-devant et a la suite de la reine Marie-Louise d'Orléans, femme de Charles II", Bulletin Hispanique, 4 (1902), pp. 104-118, 247-255 y 342-359 (p. 254 ).

17 VÁlgoma, D. de la: Norma y ceremonia de las reinas de la Casa de Austria, Madrid, Real Academia de la Historia, 1958, pp. 35 y 49. Sobre la organización de la Casa de la Reina, es de imprescindible consulta,

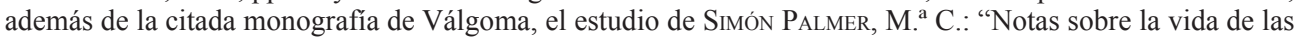
mujeres en el Real Alcázar", Cuadernos de Historia Moderna, 19 (1997), pp. 21-37. Como señala la estudiosa, los cargos administrativos y financieros están ocupados por varones (mayordomo mayor, mayordomos semaneros, caballerizo, contralor, grefier, tesorero, secretario de cámara, aposentador, etc.). Junto a estos coexiste una amplia sociedad compuesta por un número variable de mujeres, que oscila entre doscientas o trescientas empleadas, repartidas en tantas categorías como oficios y sujetas a una estricta compartimentación de tareas. Estas, desde el momento en que juran el cargo, guardan un estricto orden jerárquico, a cuya cabeza se encuentra la camarera mayor. Una vez en la planta de palacio, se les fija unos gajes, una ración de comida y casa de aposento, y reciben una gratificación en alimentos en Navidad, Carnestolendas y en los santos y aniversarios 
A pesar del magnífico recibimiento que la corte tributó a María Luisa de Orleans, con la muerte de Juan José de Austria poco antes de su llegada se encontró sin apoyos en la corte. La frivolidad de su carácter, su empeño por implantar las modas francesas en palacio y su resistencia a acatar el severo protocolo de los Austrias pronto le granjearon el odio de sus súbditos y los reproches de su camarera mayor, la temible Duquesa de Terranova $^{18}$. La persistente falta de un heredero a la corona aumentó considerablemente la impopularidad de la reina. Por todos los mentideros de Madrid resonaban día y noche coplas tendenciosas como esta, promovidas por los círculos austracistas de la corte ${ }^{19}$ :

\author{
Paríd, bella flor de lis, \\ que en fortuna tan estraña \\ si parís, parís a España. \\ Si no parís, a París.
}

de la familia real. Sobre el oficio de camarera mayor, su historia y sus funciones, véase LóPEZ-CORDón, M. ${ }^{a}$ V.: "Entre damas anda el juego: las camareras mayores de Palacio en la edad moderna", Cuadernos de Historia Moderna. Anejos, 2 (2003), pp. 123-152.

18 De las continuas querellas de la sobrina del Cristianísimo con la Duquesa de Terranova y de la turbulenta adaptación de aquella a los usos y costumbres de la corte española da buena cuenta la correspondencia de la Marquesa de Villars, esposa del embajador francés en Madrid, elegantemente editada por A. Courtois (VILLARs, Mme. de: Lettres à Madame de Coulanges (1679-1681), París, Henri Plon, 1868). Véase una espléndida síntesis en Loвato, M. ${ }^{a}$ L.: "Miradas de mujer: María Luisa de Orleans, esposa de Carlos II, vista por la Marquesa de Villars (1679-1689)", en FARré, J. (ed.): Teatro y poder en la época de Carlos II. Fiestas en torno a reyes y virreyes, Madrid, Iberoamericana, 2007, pp. 13-44. Para un análisis de los fastos en el recibimiento de la primera esposa de Carlos II, acúdase a los estudios de ZAPATA, M. ${ }^{a}$ T.: La entrada en la corte de María Luisa de Orleans, Madrid, Fusión, 2000, ToBar, M. ${ }^{a}$ L.: "Bodas de Carlos II y María Luisa de Orleans: las tres jornadas burgalesas de la fiesta", en Domínguez Matito, F. y Lobato, M. ${ }^{a}$ L. (coords.): Memoria de la palabra: Actas del VI Congreso de la Asociación Internacional Siglo de Oro, Madrid, Iberoamericana, 2004, vol. 2, pp. 1749-1762, y Benito Lázaro, M. M.: "El viaje de una reina: 1679, de París a Madrid. La jornada de María Luisa de Orleáns. El matrimonio francés de Carlos II", en LóPez-Cordón, M. ${ }^{a}$ V. y Franco, G.: Actas de la VIII Reunión Científica Española de Historia Moderna, Madrid, Fundación Española de Historia Moderna, 2005, vol. 1, pp. 585-596. Por último, véase una semblanza de la soberana en MANSAU, A.: "María Luisa de Orléans: Imágenes de la reina desde el matrimonio hasta la sepultura”, Diálogos hispánicos, 8 (1989), pp. 927-936, y López-Cordón, M. ${ }^{a}$ V.: "Las mujeres en la vida de Carlos II", en Ribot, L. A. (coord.): Carlos II: el rey y su entorno cortesano, 2009, pp. 109-140.

19 BNE, Ms. 3919, f. 88r. No es este el lugar para profundizar en el asunto, pero conviene apuntar que, desde los tiempos de Juan José de Austria, la sátira política era uno de los principales instrumentos de oposición empleados por los diferentes grupos de presión en la corte de Carlos II. En palabras de un erudito recopilador de piezas satíricas del siglo XVIII, las facciones políticas de aquel tiempo "se hacían la guerra de pluma" (BNE, Ms. 18206, f. 90v). Proliferan en este periodo de decadencia política y severa depresión económica los libelos, las hojas volanderas y los panfletos, apasionados y tendenciosos, que circulan manuscritos por corrillos cortesanos y tertulias populares, resuenan en mentideros y covachuelas y se fijan en forma de pasquines en palacios y mansiones, alimentando la avidez nunca satisfecha de los murmuradores. Sobre la sátira política en tiempos del último de los Austrias, es de imprescindible consulta el estudio de Gómez-Centurión, C.: "La sátira política durante el reinado de Carlos II", Cuadernos de Historia Moderna y Contemporánea 4 (1983), pp. 11-33. La excelente monografía de Héloïse Hermant se ocupa del examen de la sátira política y publicística desde el valimiento del padre Nithard hasta la caída de Fernando de Valenzuela (Hermant, H.: Guerres de plumes. Publicité et cultures politiques dans l'Espagne du XVII siécle, Madrid, Casa de Velázquez, 2012). Para un examen de las sátiras de los últimos años del reinado de Carlos II, acúdase al estudio de Fernández Valladares, M.: Catálogo bibliográfico y estudio literario de la sátira política popular madrileña 1690-1788, Madrid, Universidad Complutense, tesis doctoral, 1988. Por último, fundamental es también la excelente monografía de Etreros, M.: La sátira política en el siglo XVII, Madrid, Fundación Universitaria Española, 1983, que ofrece un detallado examen de estas manifestaciones literarias. 
Las facciones más hostiles comenzaban a insinuar al rey que su esposa había sido elegida por Luis XIV por su esterilidad, con el fin de que la falta de un descendiente a su muerte facilitase el paso de la corona española a manos francesas ${ }^{20}$. Asediada por la presión de quienes la consideraban una infiltrada a efectos políticos y por la inicial animadversión de Mariana de Austria, María Luisa de Orleans se solazaba cuanto podía en compañía de la numerosa servidumbre francesa ${ }^{21}$.

Poco tiempo, no obstante, pudo tener a su alcance este paliativo; la agresiva política anexionista de Luis XIV en Europa alimentaba el aborrecimiento que el contingente femenino español de la casa de la reina abrigaba contra el servicio francés. Este además tenía que soportar continuas reprimendas como cómplices o instigadores de las licencias de la soberana contra la etiqueta. La discordia palaciega crecía también con las continuas atenciones que María Luisa de Orleans dispensaba al servicio francés, lo que merecía la rotunda desaprobación de sus damas y dueñas de honor ${ }^{22}$. Tanto se agravaron las pendencias entre el servicio español y el francés de la cámara de la reina que la servidumbre francesa, incapaz de contrastar las ofensivas de sus adversarios, se vio obligada a regresar a Francia el 14 de marzo de $1680^{23}$. Únicamente permanecieron en palacio Nicole Quentin, conocida ya como Nicolasa Cantín, una sobrina suya llamada Susana Duperroy, empleada como bufetera, y la clavecinista Margarita Lautier, de la que más tarde trataremos.

La reina María Luisa, que nunca dejó de sentirse extranjera en un reino extranjero, se aferró a este pequeño grupo como a un último reducto de solaz y sosiego ${ }^{24}$. De esta coyuntura supo extraer buen provecho Nicolasa Cantín, a la que la soberana tenía un cariño más allá de toda ponderación ${ }^{25}$. El único obstáculo que embarazaba el despliegue total de las intrigas de la Cantina, a saber, la incansable vigilancia de

20 Maquart, op. cit. (nota 9), p. 63.

21 La relación entre la reina madre y la reina reinante fue tornándose amigable con el paso del tiempo, aunque conoció numerosos altibajos durante los diez años que la primera vivió en Madrid. Las fuentes contemporáneas abundan en comentarios sobre el difícil entendimiento entre ambas mujeres. Véase, por ejemplo, el billete del diplomático florentino Carlo Ridolfi, despachado en Madrid el 10 de agosto de 1681: "Las reinas madre y reinante parece que ya pasan por alguna mejor correspondencia que habemos de desear dure mucho, que bien parezca sincera y constante, siendo materia que ha ocasionado sentimiento y aun desconsuelo al rey nuestro señor la poca buena inteligencia de Sus Majestades, no siendo la edad del rey bastantemente experimentada para defenderse con valor de las asechanzas y alteraciones domésticas, conque rogamos a Dios que conserve sincera y durable la correspondencia de las reinas, porque lo contrario ocasionaría grandísimos inconvenientes, pues serviría a las pasiones de algunos de muy dañada intención" (Archivio di Stato di Firenze,

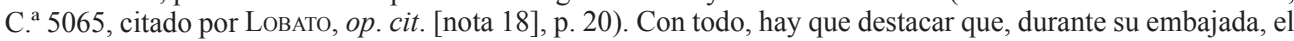
Marqués de Villars aconsejó vivamente a María Luisa de Orleans que tratase por todos los medios de congraciarse con la reina madre (VILLARS, op. cit. [nota 18], p. 163).

22 Ha quedado recogido, por ejemplo, cómo la reina María Luisa permitió que en la celebración de una festividad sus camaristas llevasen velo como las damas de honor, faltando así a la etiqueta de palacio. Las damas de honor, que representaban a las más linajudas casas nobiliarias del reino, se sintieron ultrajadas. Véase Villars, Marqués de: Mémoires de la cour d'Espagne de 1679 a 1681, ed. M. A. Morel-Fatio, París, Plon, 1893, p. 273.

23 Véase Villars, op. cit. (nota 18), p. 118-120, y MaUra, op. cit. (nota 1, 1990), p. 281.

24 LobATo, op. cit. (nota 18), p. 21.

25 Según afirmaba la clavecinista Margarita Lautier, María Luisa de Orleans "quiere a la Cantina más que a su vida" (BNE, Ms. 18755/19, f. 10Bv). En su correspondencia, el Duque de Montalto se lamenta en numerosas ocasiones de que la reina profese más amor por su antigua nodriza que por su propio marido. Así, por ejemplo, comenta que en cierta ocasión en que Carlos II cayó enfermo la soberana apenas acudió a visitarlo, 
la Duquesa de Terranova, se desvaneció en el aire cuando en agosto de 1680 la reina logró su despido. Esta fue reemplazada por la dócil Duquesa de Alburquerque, que, escarmentada con el abrupto fin de su predecesora, desempeñó lo menos posible las funciones de su cargo. Liberada ya del yugo de la camarera mayor, Nicolasa Cantín, a quien el embajador francés tachaba de falsa, ambiciosa y carente de todo escrúpulo, pudo desplegar un amplio abanico de trapacerías desde su posición privilegiada de dueña de retrete ${ }^{26}$.

La Cantina contaba con la complicidad de una dama española muy bien situada en la corte, Mariana de Aguirre, que disfrutaba de la amistad del todopoderoso Duque de Medinaceli ${ }^{27}$. Mariana de Aguirre estaba casada con Bernardino de Valdés y Girón, miembro del Consejo de cámara y junta de guerra de Indias ${ }^{28}$. La amistad de esta dama con Nicolasa Cantín se remontaba a finales de 1679; Mariana de Aguirre mantenía correspondencia con una pariente francesa lejana, la Marquesa de SaintChaumont, hermana del Mariscal de Agramont, que fue aya de María Luisa de Orleans. En una de sus cartas, la Marquesa de Saint-Chaumont pidió a Aguirre y a su marido que favoreciesen a Nicolasa Cantín cuando María Luisa de Orleans y su séquito hiciesen su entrada en la villa y corte ${ }^{29}$. Así pues, una vez en Madrid, la Cantina fue cortésmente abordada por Mariana de Aguirre. Al poco tiempo, ambas formarían una fructífera asociación.

La corte pronto asistió con estupor a los continuos trasiegos del conciliábulo formado por la antigua nodriza y su compañera española, que conseguía gajes y mercedes de todo tipo y se beneficiaba con el tráfico de cédulas reales ${ }^{30}$. Se conoce, por ejemplo, la provisión de la plaza de la secretaría del Consejo de Indias a Don Antonio Ortiz de Otalora, que había sido guardajoyas de la reina María Luisa y estaba casado con una sobrina de la Cantina llamada Margarita Duperroy. En un primer momento, en 1680 ó 1681, el Duque de Medinaceli había vetado el nombramiento, pero finalmente la aspiración del Duque a congraciarse con la reina para asegurar su permanencia al frente del gobierno propició en 1684 la provisión de dicha plaza en la persona

mientras que siempre que sangraban a la Cantina, pasaba a verla de todos modos y a todas horas (MonTALTO, op. cit. [nota 5], p. 316, 25 de mayo de 1685).

26 Villars, op. cit. (nota 22), p. 238.

27 Lobato, op. cit. (nota 18), p. 21.

28 Bernardino de Valdés, hijo de Diego Pérez Valdés, fue alférez de infantería y caballería y alcalde de las guardas de Castilla, hasta que el 26 de febrero de 1677 ocupó el sillón de consejero de Indias, cargo que, salvo un periodo de cesación forzosa, ocupó hasta su muerte, ocurrida el 13 de noviembre de 1695 (SCHÄFER, E.: El Consejo Real y Supremo de las Indias: historia de la organización del Consejo y de la Casa de la Contratación de Indias, Madrid, Junta de Castilla y León, 2003, vol. 1, p. 347).

29 BNE, Ms. 18755/19, f. 16Br; MAURA, op. cit. (nota 1, s.a.), p. 129.

30 Villars, op. cit. (nota 22), p. 244. 
de Antonio Ortiz ${ }^{31}$. La Cantina también logró prebendas para el galán de su sobrina Susana, llamado Juan de Chavarría, que era cerero mayor de la reina madre ${ }^{32}$.

$\mathrm{Al}$ valimiento de Mariana de Aguirre en la cámara de la reina parece deberse el feliz desenlace de un episodio que pudo haber acabado con la carrera de su esposo, Bernardino de Valdés; este, a finales de 1683, ordenó el registro exhaustivo de la carroza del nuncio Millini cuando esta cruzaba la Puerta de Toledo. El nuncio, descompuesto por aquel atropello a su inmunidad diplomática, entregó un memorial al rey, por el que Valdés fue prestamente encarcelado. Sin embargo, el 6 de diciembre de ese mismo año, el Consejo de Estado decidió restituirlo a su plaza. Aunque Millini protestó enérgicamente, alegando que el papa Inocencio XI pedía mayores satisfacciones, el flamante marido de Mariana Aguirre continuó ejerciendo su antiguo puesto ${ }^{33}$.

A este reducido conciliábulo pronto vino a sumarse un nuevo personaje. Se llamaba Juan de Viremont y había nacido en torno al año 1649 en Normandía ${ }^{34}$. Gracias a la declaración de su criado Pedro Burlé, recogida en el auto del proceso, sabemos que Viremont vivió en París, Turín y Poitiers ${ }^{35}$. Su prometedora carrera militar, en la que fue distinguido con el grado de capitán de granaderos, hizo aguas cuando, durante el sitio de Limburgo en 1675, se batió en duelo con un caballero francés al que dio muerte ${ }^{36}$. Condenado al destierro, Viremont pasó a España, donde cuatro años después entró como caballerizo al servicio del Marqués de Villars, embajador de Luis XIV en Madrid desde el 25 de junio de 1679. Las funciones de Viremont en la embajada francesa, sin embargo, trascendían las propias de un mero caballerizo y eran más consecuentes con las de un agente oficioso; así, al poco tiempo de llegar la reina María Luisa a España, Viremont pasó a Inglaterra por orden del Marqués de Villars con un pliego del enviado de Portugal ${ }^{37}$.

Poco tiempo permaneció Juan de Viremont al servicio de la embajada, ya que en 1681 Carlos II solicitó al Cristianísimo el relevo del Marqués de Villars, acusándolo de dar consejos imprudentes a la reina y de entremeterse en la política interior sir-

31 A este respecto es ilustrativo el comentario del Duque de Montalto: "El primer ministro hace grandes diligencias para tener gustosa a la reina, de cuyas aldabas se ha asido para su conservación y cueste lo que costare, que, como no sale de patrimonio propio, siempre le parecerá barato" (MonTALTo, op. cit. [nota 5], p. 306, 15 de marzo de 1685). Sobre el nombramiento del citado Antonio Ortiz, véase ScHÄFER, op. cit. (nota 28), p. 354. Consúltese también la correspondencia del Conde de La Vauguyon, embajador francés en Madrid en 1683, que describe los desvelos de la reina María Luisa por lograr dicho nombramiento (AMAE, Correspondance Politique, Espagne, t. LXVIII, ff. 101r y 205r-v).

32 Montalto, op. cit. (nota 5), p. 323, 1 de agosto de 1685. La relación amorosa que mantenían Juan de Chavarría y Susana Duperroy es revelada en la correspondencia del embajador Heemskerk (AMAE, Correspondance Politique, Espagne, t. LXIX, f. 241r).

33 Archivo Secreto Vaticano, Nunciatura apostólica, Nunciatura de Madrid, C. ${ }^{a}$ 11, Legs. 6-14 y 28-37. Sobre las actividades diplomáticas del nuncio Millini en su estancia en Madrid, véase el detallado estudio de MARQués, J. M.: La Santa Sede y la España de Carlos II: la negociación del nuncio Millini 1675-1685, Roma, Instituto Español de Historia Eclesiástica, 1981.

34 BNE, Ms. 18755/19, f. 6Br; VILlars, op. cit. [nota 22], p. 318. El apellido de este normando, como suele suceder con numerosos antropónimos franceses, se deforma de muy variadas maneras en la documentación de la época, lo que dificulta considerablemente su indagación. Así, encontramos variantes como Vilmont, Virmont, Virmonte, Biomont, Videmont, Belmonte o incluso Boybón.

35 BNE, Ms. 18755/19, f. 12Av.

36 Dangeau, Marqués de: Mémoires, ed. Mme. de Genlis, París, Treutel y Würtz, 1817, t. I, p. 134.

37 BNE, Ms. 18755/19, ff. 6Ar y 6Bv. 
viéndose para ello de su esposa, Marie de Bellefonds ${ }^{38}$. Viremont, que a causa de su desafío en Limburgo no podía regresar a Francia con el embajador, tomó entonces la resolución de pasar a Flandes con el Marqués de Grana. No obstante, antes de su partida, el Marqués de Villars solicitó a María Luisa de Orleans que el antiguo militar se quedase en Madrid a su servicio, empleando para ello como mediadora a la Cantina. La reina, deseosa de complacer a su antigua nodriza, se afanó entonces en purgar los naturales recelos de su esposo, que veía con malos ojos la introducción en palacio de un criado de la embajada francesa. Por fin, Viremont fue admitido en las caballerizas de la reina con la condición de que "no tuviese correspondencia con el de Vilar" 39. Una vez en palacio, el normando se ganó la voluntad de María Luisa de Orleans y la aprobación de Carlos II, al tiempo que estrechaba lazos con su primera valedora, Nicolasa Cantín. A la postre, ambos empleados reales vinieron a ser amantes.

Tras la destitución del Marqués de Villars, el Cristianísimo envió a Madrid a André de Bétoulat de la Petitière, Conde de La Vauguyon, sujeto seductor, perspicaz, astuto e intrigante, que trató de influir sobre la reina María Luisa para que, tras el ataque de hemiplejía del Duque de Medinaceli en 1683, sugiriese a Carlos II el nombramiento de un primer ministro de escasa competencia. Tras la declaración de guerra con Francia a finales de aquel año, el Conde de La Vauguyon recibió orden de partir hacia el Bidasoa, donde fue canjeado por el embajador español en París, el Marqués de la Fuente. Firmada la tregua de Ratisbona en agosto de 1684, la embajada gala en Madrid permaneció sin delegado durante medio año más. Finalmente, el 26 de marzo de 1685 llegó a Madrid el sucesor del Conde de La Vauguyon, Isaac de Pas, Marqués de Feuquières, enviado con urgencia para tratar el espinoso asunto del matrimonio entre el Elector de Baviera y la Archiduquesa María Antonia de Austria ${ }^{40}$. Según la colorida semblanza que nos proporciona Maura, el Marqués de Feuquières era un anciano general adusto y flemático, desconocedor de la lengua castellana y lastrado por una visión deformada de la realidad española, avivada por los novelescos y extravagantes rumores que le hacían llegar su secretario La Vasseur y el Duque de Camiña, informador oficioso de la corte ${ }^{41}$. El Marqués tenía órdenes de celebrar cuantas entrevistas

38 MaUra, op. cit. (nota 1, 1990), p. 286. Según un despacho del Marqués de Villars a Luis XIV, fechado el 20 de febrero de 1681, el rey de España había ordenado su expulsión porque "excediendo de su ministerio se interesan a pláticas y negociaciones que, no teniendo dependencia alguna con los intereses de Vuestra Majestad Cristianísima ni de su corona, son muy perjudiciales a las cosas internas del gobierno y a las domésticas de su palacio" (AMAE, Correspondance Politique, Espagne, t. LXVII, ff. 234v-235r). Cito el documento por la traducción de LoBATO, op. cit. (nota 18), p. 19.

39 BNE, Ms. 18755/19, f. 7Ar.

40 El Duque de Montalto registra en los siguientes términos la llegada del embajador francés y sus propósitos: "El motivo principalísimo que ha mantenido al Marqués de Grana en su gobierno ha sido haber promovido por medio de la reina madre los tratados de casamiento del Duque de Baviera con la señora Archiduquesa, los cuales llegaron a complemento, dándola por dote los Países Bajos, sobre que se formó aquí Junta de Estado y convinieron en ello, pero habiéndolo entendido el rey de Francia envió aquí su embajador y vino por la posta y dio el papel [...], de que resultó haber habido el domingo pasado Consejo de Estado en presencia del rey y concurrieron cuantos se hallan en esta corte [...]. La resolución que se ha tomado hasta ahora no se sabe fundamentalmente, pero no habrá que dudar que habrá de ser cediendo a lo que el Cristianísimo quisiere" (Montalto, op. cit. [nota 5], p. 309, 12 de abril de 1685).

41 Maura, op. cit. (nota 1, 1990), pp. 314-315. Con respecto a la función del Duque de Camiña, gentilhombre de cámara de Carlos II, en la nube de desinformación que cegaba al Marqués de Feuquières, véase MAURA, op. cit. (nota 1, s.a.), pp. 153-154. 
pudiera con la reina María Luisa, con la prevención de no despertar sospechas de inteligencia, lo que años atrás había originado la expulsión del Marqués de Villars. El diplomático debía guiar la conducta la reina con una serie de directrices dictadas en Versalles, con el fin de que esta influyera en su marido para que nombrara los ministros que el Rey Cristianísimo considerase adecuados para sus fines ${ }^{42}$. Dada la particular propensión de la reina María Luisa a desentenderse de los asuntos políticos, se hacía imperativa la asiduidad de las visitas del embajador ${ }^{43}$. No obstante, el Marqués de Feuquières se encontró con un obstáculo del todo imprevisto que entorpecía, si no abortaba, el cumplimiento de sus órdenes diplomáticas; Nicolasa Cantín y Mariana de Aguirre habían secuestrado de tal modo la voluntad de la reina María Luisa que esta hacía oídos sordos a las recomendaciones y admoniciones que proviniesen de cualquier otra persona ${ }^{44}$. Feuquières se encontraba con las manos atadas.

En la primavera de 1685, el galanteo de Juan de Viremont y Nicolasa Cantín propició un nuevo escándalo en palacio, como relata el Duque de Montalto ${ }^{45}$ :

V.E. ya sabrá que madama Cantín es la valida de nuestra reina y que Mr. Biomont, un francés a quien la reina ha fiado el manejo y cuidado de los caballos de su persona y que también es bien visto de su majestad. Por esta razón, se introdujo tanto este hombre con la Cantín que, aunque trae el traje de dueña y no es muy niña ni nada de hermosa, puso en plática querer casarse con ella. De esto se hacía risa en el lugar, pero ha pasado tan adelante y con tal estrechez el galanteo que ni a ella le faltaba habilidad para salir a pasearse ni a él tampoco para lograr quizás el haber entrado en su posada. $\mathrm{Y}$, séase como se fuere, últimamente sacaron a esta mujer de palacio y la llevaron a casa de Doña María Ana de Aguirre, mujer de Don Bernardino de Valdés, la cual está en gran valimiento de la reina, y dicen parió un muchacho pocos días ha, habiendo causado este escándalo la mayor murmuración y sátiras tan desvergonzosas que no se puede ponderar bastantemente ni tampoco la irresolución del rey, que es como tengo dicho a V.E.

Poco después del nacimiento del niño, los amantes se casaron un 8 de abril de 1685 , en un tenso ambiente de protestas y murmuraciones, como refiere el embajador veneciano $^{46}$. El descontento creció aún más cuando corrió la voz de que la casa de la reina había pagado la dote de la dama francesa, que ascendía a siete mil doblones, como denunciaba una sátira contemporánea ${ }^{47}$. Como era acostumbrado en estos casos, al

42 Álvarez López, A.: "Los negocios de Luis XIV en Madrid: la acción de sus embajadores en la corte madrileña", Revista de Historia Moderna, 25 (2007), pp. 179-205 (p. 200).

43 En su correspondencia, la Marquesa de Villars registra en varias ocasiones la escasa implicación de la reina María Luisa en los planes estratégicos de la corte francesa. Véase, por ejemplo, el siguiente pasaje: "Elle ne se divertit pas trop à raisonner sur la politique" (VILlars, op. cit. [nota 18], p. 163). Sobre la función política que desde Versalles se asignó a la reina María Luisa en la corte madrileña, véase SÁNCHEz GonZÁLEZ, R.: "Consejos a una reina. Instrucciones de la diplomacia francesa a María Luisa de Orleans, primera esposa de Carlos II", en López-Cordón, M. ${ }^{a}$ V. y Franco, G., op. cit. (nota 18), pp. 575-584.

44 Así lo denuncia el embajador veneciano en su correspondencia (ASVE, Senato, Dispacci degli ambasciatori, Spagna, C. ${ }^{\text {a }} 123,9$ de agosto de 1685).

45 Montalto, op . cit. (nota 5), p. 310, 12 de abril de 1685.

46 ASVE, Senato, Dispacci degli ambasciatori, Spagna, C. ${ }^{\text {a }} 121,12$ de julio de 1685.

47 BNE, Ms. 3921, f. 256r. 
día siguiente de la boda, el 9 de abril, Nicolasa Cantín perdió los gajes de enfermería y la ración de criada, ya que, según el protocolo, las empleadas en la cámara de la reina no podían permanecer en palacio después de casarse ${ }^{48}$. Sin embargo, María Luisa de Orleans decidió incorporarla de nuevo al servicio, quebrantando así la etiqueta de palacio $^{49}$. El 11 de abril de 1685 Nicolasa Cantín, vestida de gala, acudió a besar la mano de los reyes y al día siguiente, por mandato de la sobrina del Cristianísimo, le fueron restituidos los gajes de enfermería y la ración de criada ${ }^{50}$. Poco después, los recién casados promovieron un nuevo escándalo al acudir a la jornada de Aranjuez "con el tren que pudiera la persona de mayor esfera y con carruaje de la casa real"

Asegurados en el anchuroso valimiento de la reina, Viremont y su esposa se veían protegidos contra cualquier toda adversidad. No obstante, pocos meses más tarde, dos compatriotas suyos, Margarita Lautier y Pedro Levillane, amparados también por altos poderes, lograron abatir su bastión y propiciar su ruina, movidos por una antigua rivalidad.

\section{ACUSACIONES CRUZADAS}

Margarita Lautier, nacida en torno al año 1660, natural de la Provenza, era una avezada clavecinista ${ }^{52}$. En 1679 se incorporó en Fontainebleau al servicio de María Luisa de Orleans y fue acogida en el nutrido séquito de instrumentistas, lutieres y cantantes que, bajo la dirección del violinista Michel Farinelli, acompañó a la joven princesa a España ${ }^{53}$. Como antes he apuntado, cuando la servidumbre francesa retornó a Francia en marzo de 1680, Lautier permaneció al servicio de la reina, junto con Nicolasa Cantín y la bufetera Susana Duperroy, sobrina de la Cantina. Un año más tarde, el 28 de agosto de 1681, la clavecinista salió de palacio para casarse con el francés Pedro Levillane ${ }^{54}$.

Levillane, nacido como Margarita Lautier en torno al año 1660, había servido en las caballerizas del Marqués de Villars en Madrid, donde tuvo ocasión de conocer a Juan de Viremont ${ }^{55}$. En ese periodo, la reina María Luisa solicitó al embajador francés un picador para sus caballerizas. El Marqués de Villars ofreció el puesto a Viremont, pero este, que se disponía a partir a Inglaterra en misión diplomática, recomendó promover al joven Levillane ${ }^{56}$. Este, tras ser empleado como picador, inició una prometedora carrera en la caballeriza de la reina; el 21 de marzo de 1681 fue ascendido a caballerizo de los cuartagos, sucediendo en el puesto a Pedro de Zárate,

48 Sobre el alcance y significación de estos gajes, véase Simón PALMER, op. cit. (nota 17), pp. 36-37.

49 Montalto, op. cit. (nota 5), p. 313, 25 de abril de 1685.

50 Ibidem, p. 310, 12 de abril de 1685. Véase el expediente personal de Nicolasa Cantín conservado en el Archivo General de Palacio, que da cuenta de la restitución de sus gajes (AGP, Personal, C. ${ }^{\text {a }} 16727$, Exp. 2).

51 Montalto, op. cit. (nota 5), p. 313, 25 de abril de 1685.

52 BNE, Ms. 18755/19, f. 2Bv; VILLARS, op. cit. (nota 22), p. 318.

53 Sobre el séquito de músicos que acompañó a la esposa de Carlos II en 1679, véase Benort, M.: "Les musiciens français de Marie-Louise d'Orléans, Reine d'Espagne", Revue Musicale, 226 (1955), pp. 48-60.

54 Recoge la fecha referida el expediente personal de Margarita Lautier (AGP, Personal, C. a 577, Exp. 37).

55 BNE, Ms. 18755/19, ff. 6Bv y $10 \mathrm{Av}$.

56 Ibidem, f. 6Ar. 
y el 5 de octubre de 1682 fue ascendido a caballerizo honorario, lo que lo situaba muy cerca de obtener la plaza entera de caballerizo de campo ${ }^{57}$.

A pesar de que Levillane debía a Viremont su ingreso en palacio, cuando este último se incorporó a la caballeriza de la reina en 1681, se originó una tensa rivalidad; ambos competían por medrar en las caballerizas reales, al amparo del valimiento de sus respectivas esposas en la cámara regia. No obstante, la gracia de la reina brillaba con más fuerza sobre la esposa de Viremont, de modo que, en palabras del Duque de Montalto, en la caballeriza no había "más autoridad de jefe que la de Biomont y este tan audaz que pretendió los honores de caballerizo mayor expresos, aunque tácitos los lograba" 58 .

Levillane, que veía del todo frustradas sus ambiciones, resolvió emplear todos los medios a su alcance para deshacerse de su principal adversario. Así, tanto él como su esposa divulgaron el rumor de que, tras la partida del Marqués de Villars, Viremont se había quedado en España como espía. Cuando, en agosto de 1684, María Luisa de Orleans encomendó a Juan de Viremont que partiese a Francia para comprar unos caballos rabones, de donde regresó con ellos a principios de 1685, el matrimonio redobló sus acusaciones de espionaje ${ }^{59}$. Entendían que, dado que Luis XIV había castigado por batirse en duelo "a más de veinte personas de los primeros señores y generales de la Francia, sin haber bastado humana diligencia a restituirlos", Juan de Viremont debía de ser un "instrumento de alguna gran confidencia a cuyo título había ganado el perdón", ya que había entrado en Francia sin ser encarcelado ${ }^{60}$.

No solo Juan de Viremont se hizo acreedor de graves acusaciones por parte de Levillane y su esposa; también Nicolasa Cantín se vio en aprietos semejantes a principios de 1681, cuando Margarita Lautier la acusó de un delito de envenenamiento. La clavecinista afirmaba que había visto con frecuencia cómo la antigua nodriza suministraba una bebida a la reina a escondidas y en las ocasiones en que el rey no podía verlo, por estar fuera de palacio o en su despacho. Como aquel comportamiento le parecía sospechoso, Lautier resolvió probar el brebaje, a resultas de lo cual padeció unos dolores de vientre agudísimos. También aseguraba que la Cantina acostumbraba a dar a la reina ciertas píldoras, cuando esta tenía algún retraso menstrual. Fingiendo un dolor de cabeza, Margarita Lautier pidió una de aquellas grageas a María Luisa de Orleans y, al probarlas, sintió que le ardían las entrañas. Al cabo de dos días, sufrió una inusitada evacuación de flujo menstrual "con notable copia y tal que parece se había desatado naturaleza y nunca antes ni después con tal abundancia ni en esta forma le ha sucedido" ${ }^{61}$. Fuera todo esto cierto o una mera calumnia nacida del rencor, lo cierto es Lautier acudió entonces a la camarera mayor, la Condesa de Alburquerque,

57 Véase el expediente personal de Pedro Levillane conservado en el Archivo General de Palacio (AGP,

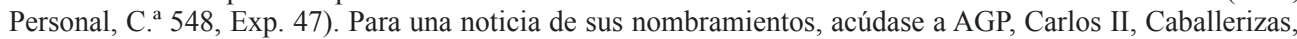
Leg. 16/11. Sobre la organización de la real caballeriza de María Luisa de Orleans, consúltese el espléndido estudio de Serrano García, E.: "Los empleos en la caballeriza de la reina durante el reinado de Carlos II: mecanismos de transmisión", Anuario de Historia del Derecho Español, 63-64 (1993-1994), pp. 1041-1064.

58 Montalto, op. cit. (nota 5), p. 323, 1 de agosto de 1685.

59 BNE, Ms. 18755/19, f. 6Av. La fecha de regreso de Juan de Viremont a España con los caballos rabones se colige del f. $12 \mathrm{Av}$.

60 Ibidem, f. 3Br.

61 Ibidem, f. $1 \mathrm{Bv}$. 
y a la esposa del primer ministro, la Duquesa de Medinaceli, y acusó a la Cantina de suministrar abortivos a la reina María Luisa para impedir la sucesión de Carlos II. No obstante, ninguna de aquellas dos señoras dio crédito alguno a tan inusual acusación ${ }^{62}$. Con todo, Viremont y su esposa, que veían peligrar no solo su fecundo emporio sino también su cabeza, acusaron a Levillane de robo en las caballerizas de la reina, probablemente en junio de 1685, por lo que este fue desposeído de su cargo.

La pésima situación financiera de Levillane, cuyo modo de vida había quedado por siempre truncado, lo condujo irremediablemente a la desesperación. Poco después de su destitución, el antiguo caballerizo pidió al capitán de caballos Arnesto Gorci que buscase a Viremont para que le dijera que saliese al campo a reñir con él, ya que, "pues le había dejado sin pan para su mujer y hijos, [...] poco importaba le quitase la vida" ${ }^{63}$. El normando, no obstante, rehusó batirse con Levillane, recordando los graves problemas que le había acarreado su pasado desafío en Limburgo. Según parece, Levillane meditó también la posibilidad de acuchillar a Viremont en la Casa del Campo o acabar con su vida dándole a beber un caldo donde había molido un diamante ${ }^{64}$. Enterados de todo ello Nicolasa Cantín y Viremont, hallaron el modo de librarse de una vez por todas de aquella molesta pareja; la Cantina acudió a la reina y le contó los supuestos planes de Levillane para acabar con la vida de su marido. Aquello precipitó de modo irreparable los acontecimientos.

\section{LA PARTIDA}

Entró entonces en escena Mariana de Aguirre, que procedió a hostigar a Margarita Lautier y Pedro Levillane empleando para ello a uno de sus criados de espada llamado Isidro Espinosa de los Monteros. El día 20 de junio de 1685 este criado acudió al domicilio de Levillane y Lautier, que vivían en uno de los cuartos de la casa de una tal María Martínez, viuda del alguacil de corte Manuel Calvo. Espinosa de los Monteros pidió a esta viuda que escribiese un memorial de su puño y letra en el que diera noticia de sí misma y de sus inquilinos. Martínez, que se asustó tanto por la torva presencia del visitante como por su inusitada petición, despachó al criado sin atender su requerimiento. Cuando aquella misma noche llegaron Lautier y su esposo, su casera les contó todo lo sucedido. Pedro Levillane dijo entonces que, posiblemente, aquella diligencia era para "bajar decreto para echar de aquí a él y su mujer" ${ }^{65}$. Sospechaba el antiguo caballerizo que los esbirros de Mariana de Aguirre tenían orden de prenderlos y meterlos "de golpe en una litera que a este efecto se había tomado en la calle de

62 Ibidem, ff. $1 \mathrm{Bv}-2 \mathrm{Br}$.

63 BNE, Ms. 18755/19, f. 16Ar. Identifico al sujeto que recibe el nombre de "Arnesto Gorci" en el auto con Ernesto Hernando Gorcey y Kessel, natural de Luxemburgo, capitán de caballos corazas españoles, que en 1688 recibió el hábito de caballero de la Orden de Santiago (AHN, Órdenes militares, Caballeros de Santiago, Exp. 3588). Era hijo de Margarita de Kessel y Bernardo de Gorcey, teniente de la guarda alemana del rey. Véase Chenaye-Desbois, F. A. A. de la: Dictionnaire de la noblesse, París, Antoine Boudet, 1774, t. VII, p. 308 .

64 BNE, Ms. 18755/19, f. 5Bv.

65 Ibidem, f. 8 Ar. 
Alcalá y que esto era dispuesto y votado por la $\mathrm{Ag}[\mathrm{u}]$ irre, la Cantina y Vilmonte y sin orden del Rey" ${ }^{\prime 6}$.

Margarita Lautier entró en pánico y decidió ocultarse en casa de unas vecinas, en la calle de San Bernardo. Allí permaneció cobijada, hasta que al día siguiente su marido acudió a buscarla y regresaron a su hogar. Cuando, al caer la noche, Levillane dejó sola a su mujer, acudió de nuevo al lugar Isidro Espinosa de los Monteros. Este informó a María Martínez de que el memorial que le pidió había sido solicitado por la reina María Luisa en persona y, tras anunciar que quería hablar con Pedro Levillane, se metió en el cuarto del matrimonio. Encontró allí sola a Margarita Lautier, que echó a correr en camisa dando altas voces. Al bajar la escalera, se encontró con su casera, que la sosegó como pudo, mientras Isidro Espinosa de los Monteros aprovechaba la ocasión para escabullirse y salir a la calle.

El viernes 22 de junio Isidro Espinosa de los Monteros regresó de nuevo a aquel domicilio. En aquella ocasión, encontró en casa a Pedro Levillane y le informó de que su señora quería hablar con él. La entrevista que tuvo lugar entre Mariana de Aguirre y Pedro de Levillane, en la que no hubo testigo alguno, fue descrita en el auto del proceso de modo muy diverso por este y por aquella. Mientras que Aguirre aseguró que se limitó a señalar a Levillane que la reina deseaba que volviese a Francia con su esposa, Levillane sostenía que Mariana de Aguirre le advirtió de que, si contaban al conde de Oropesa algo acerca "de las cosas de la Cantina y Virmonte", peligraría su cabeza, "aunque estuviese al cabo del mundo" ${ }^{67}$. Al día siguiente, sábado 23 de junio, Mariana de Aguirre citó de nuevo a Pedro Levillane. Según este, la dama recurrió a toda suerte de halagos, proponiéndole participar de los beneficios arrancados a la reina, pero no consiguió torcer la voluntad del francés. Ese mismo día, Pedro Levillane partió con su mujer al destierro.

Isidro Espinosa de los Monteros hizo entonces una última visita a la casa de María Martínez; una vez en presencia de la viuda, le pidió las llaves del cuarto del matrimonio en nombre de Mariana de Aguirre, que se ofrecía a cuidar de ellas. La viuda despachó al criado con cajas destempladas, tras replicar que "aquellos vecinos tenían pagado adelantada la vivienda y harían de las llaves lo que quisiesen" 68 .

\section{LA DENUNCIA}

El matrimonio francés tomó el camino de Valencia y se detuvo en Cuenca. Allí Pedro Levillane escribió un memorial con la tibia esperanza de cobrarse una tardía venganza. Dado que la denuncia de la Cantina como ejecutora principal de una conspiración para impedir el nacimiento de un heredero a la corona no había atraído la atención de los altos poderes, Levillane pergeñó una acusación más apremiante; así, escribió un memorial en el que acusaba a la antigua nodriza y su esposo de tener planeado envenenar al rey de España ${ }^{69}$. Para dar color de verdad a su acusación, Levillane añadió

\footnotetext{
66 Ibidem, f. 11Ar.

67 Ibidem, f. 3Bv.

68 Ibidem, f. 8Br.

69 BNE, Ms. 11017, f. 221r.
} 
que las tropas francesas que desde mayo de 1685 se arremolinaban en la frontera con Navarra y Cataluña no hacían sino aguardar la muerte del monarca para invadir el reino ${ }^{70}$.

Una vez redactado el memorial, Levillane envió una copia a la reina madre, que, como era de esperar, no dudó en ignorar la denuncia, pues suponía que el acusador se había movido a ello por despecho. Levillane despachó entonces el memorial al Conde de Oropesa, primer ministro de facto de la monarquía, como antes se ha apuntado. Como hiciera previamente Mariana de Austria, Oropesa menospreció el pliego, arguyendo, en referencia al supuesto complot para asesinar a Carlos II, "que esas cosas solían ejecutarse antes que decirse" 71 . Levillane quiso entonces probar fortuna con el Conde de Mansfeldt, embajador del emperador Leopoldo en Madrid, que, en palabras de Pfandl, "se halló entre bastidores en todas las maniobras que se llevaron a cabo durante esos años en interés de Austria y en perjuicio de Francia"72. Mansfeldt acogió más que gustoso la denuncia del caballerizo despechado. Alumbrado por su proverbial astucia política que desplegaba con una maestría sin escrúpulos, Mansfeldt tuvo la audaz idea de divulgar a los cuatro vientos la noticia de que la vida del Carlos II peligraba, en el marco de una intriga urdida en los camarines de Versalles. Poco después, los rumores resonaban con fuerza en todas las plazas y mentideros de Madrid, excitando la indignación popular, aún palpitante tras el motín francófobo que había estallado en la villa en $1683^{73}$.

No sabemos si la novelesca denuncia de Levillane, imaginativamente reelaborada por Mansfeldt, mencionaba la participación en el complot de la reina María Luisa, pero lo cierto es que los rumores que circularon por Madrid apuntaban en aquella dirección ${ }^{74}$. La divulgación de estas hablillas se vio favorecida por la impopularidad de la reina, complicada en las intrigas que tejían en torno a ella los sucesivos embajadores franceses y la camarilla francesa que prosperaba a su calor. El pueblo, que responsabilizaba a María Luisa de Orleans de la doliente falta de un heredero a la corona, acogió y promovió los rumores que hacían de ella un perverso instrumento de las maquinaciones del Cristianísimo.

Cuando el rumor llegó a palacio, la situación fue aprovechada por los sectores francófobos de la corte para hostigar a la reina, acusándola de alta traición, aunque el rey no vaciló en defender la inocencia de María Luisa de Orleans ${ }^{75}$. Con todo, dada

70 Sobre la concentración de las tropas francesas en la frontera en aquel tiempo, véase ASVE, Senato, Dispacci degli ambasciatori, Spagna, C. ${ }^{\text {a }} 121,12$ de julio de 1685 y 9 de agosto de 1685 . El Duque de Montalto escribe al respecto: "Estase con recelos de que las tropas del Cristianísimo invadan el reino de Navarra, para donde se han enviado algunos reformados y se hacen levas en esta corte y comienzan ya marchar algunas compañías" (Montalto, op. cit. [nota 5], p. 315, 10 de mayo de 1685).

71 BNE, Ms. 18755/19, f. 17Av.

72 Pfand, op. cit. (nota 2), p. 240.

73 Kamen, op . cit. (nota 2), p. 283.

74 BNE, Ms. 18755/19, ff. 17Av-Br.

75 En sus memorias, el Marqués de Sourches se hace eco del voto de confianza de Carlos II: "Ce prince avoit témoigné n'y ajouter aucune foi et avoir trop de confiance en la vertu et en l'amitié de la reine pour la soupçonner d'un pareil attentat" (Sourches, Marqués de: Mémoires secrets et inédits de la Cour de France sur la fin du règne de Louis XIV, ed. A. Bernier, París, Beauvais Ainé, 1836, t. I, p. 257). El embajador Sebastiano Foscarini apunta un juicio similar en su correspondencia (ASVE, Senato, Dispacci degli ambasciatori, Spagna, C. ${ }^{\text {a }} 121,26$ de julio de 1685$)$. 
su atávica desconfianza de toda persona francesa (salvo su esposa), Carlos II ordenó la inmediata intervención del Conde de Oropesa. Este, que no daba crédito a las acusaciones de envenenamiento que había leído en el memorial de Pedro Levillane, intuyó no obstante las ventajas políticas que podían desprenderse de aquel caso; por un lado, si purgaba la casa de la reina, pondría coto a la relevancia que iba adquiriendo el partido francés en la corte. Por otro lado, como ya se ha apuntado, al poner orden en aquel asunto, haría ostentación de su poder ante las facciones cortesanas y grupos clientelares afines al Duque de Medinaceli.

El Conde de Oropesa encargó la instrucción del sumario al licenciado Francisco Bravo de Sobremonte y Pérez, alcalde de casa y corte y caballero de la Orden de Santiago, que el 20 de octubre de 1680 había sido nombrado juez conservador de los franceses de Madrid. Esta judicatura le confiaba la jurisdicción criminal de los súbditos galos, que debían dirigirse a él en todos sus procesos, ya fuese en calidad de acusados o como denunciantes ${ }^{76}$.

Carlos II ordenó, además, la creación de una Junta ad hoc que, presidida por el Conde de Oropesa, se ocuparía de examinar el caso $^{77}$.

\section{EL PROCESO JUDICIAL}

El proceso que se instruyó al socaire de las denuncias de Margarita Lautier y Pedro Levillane acaparó durante las semanas siguientes la atención de la población madrileña, que dependía únicamente de especulaciones y rumores vagos, ya que el celo con que se emprendieron las diversas diligencias fue tan escrupuloso que apenas hubo filtraciones ${ }^{78}$.

La primera medida que estableció la Junta presidida por el Conde de Oropesa fue la detención expeditiva de Levillane y Lautier en la ciudad de Cuenca y su inmediato traslado a Madrid para ser sometidos a interrogatorio. En cumplimiento de la orden, los dos franceses fueron capturados y trasladados a la villa a principios de julio de 1685. Levillane fue puesto en custodia en una de las torres de la cárcel de corte y Margarita Lautier fue recluida en la vivienda del alguacil Francisco de Salas, en la calle del Duque de Alba.

El martes 10 de julio de 1685, Francisco Bravo de Sobremonte procedió a interrogar a Margarita Lautier. Esta acusó a la Cantina de suministrar abortivos a la reina María Luisa, denunciando la administración de un brebaje de color amarillo y de unas píldoras "de harta mala calidad", así como de triaca, que Nicolasa Cantín ofrecía a la soberana "después de la cena y a otras horas también, a escondidas, con el engaño de

\footnotetext{
76 Girard, A.: El comercio francés en Sevilla y Cádiz en tiempo de los Habsburgo, Sevilla, Centro de Estudios Andaluces, 2006, p. 167.

77 Según puntualiza en su correspondencia Sebastiano Foscarini, la junta estaba formada "degli piu accreditati soggetti del Consiglio Reale giudicará con l'autorità di tutto il Consiglio per speciale decretto di S.M." (ASVE, Senato, Dispacci degli ambasciatori, Spagna, C. ${ }^{a} 121,26$ de julio de 1685).

78 El embajador veneciano afirmaba que el proceso contra la Cantina fue "l'unico negotio che da gran tempo sia si trattato in Spagna con impenetrabilità di segretto" (ASVE, Senato, Dispacci degli ambasciatori, Spagna, C. ${ }^{\text {a } 123,9}$ de agosto de 1685$)$.
} 
decir se lo daba a Su Majestad a fin de que se perservase [sic] por si en España la daban algún veneno"79. Lautier acusó también a Juan de Viremont de colaborar secretamente con Luis XIV, que le habría concedido el indulto por el homicidio en Limburgo a cambio de que asegurase la falta de sucesión de María Luisa de Orleans. Por último, la antigua clavecinista aseguró la participación en el delito del círculo de amigos de la Cantina, formado por Juan de Chavarría, cerero de la reina madre, como ya se ha apuntado, Mariana de Aguirre, Juan Bautista Fornó y un mercader apellidado Patú.

Ese mismo día, el juez interrogó a Pedro Levillane en la cárcel real. En su declaración, el antiguo caballerizo insistió en tachar a Juan de Viremont de espía del Cristianísimo, con el cual habría departido Viremont en su estancia en Francia en el último cuatrimestre de 1684. Levillane acusó también a Mariana de Aguirre de tratar de encubrir las intrigas de la Cantina y de abusar de la confianza de la reina.

A continuación, el mismo día 10 de julio, Francisco Bravo de Sobremonte dio cuenta de las declaraciones de Lautier y Levillane al Conde de Oropesa. Una vez enterado de los pormenores del caso, Oropesa procedió con la cautela que lo distinguía, sabedor de que sus adversarios en la corte, principalmente los satélites del Duque de Medinaceli, aprovecharían la más leve omisión en materia tan importante para atacarlo y llevarlo a la ruina, como apuntaba en su correspondencia el embajador de Venecia $^{80}$. Con el fin de sopesar cuidadosamente las implicaciones políticas del caso, Oropesa ordenó a Bravo de Sobremonte que no emprendiese ninguna otra diligencia hasta que se le ordenase ${ }^{81}$.

En el ínterin, la agitación popular seguía en aumento. En el centro de todas sus iras se encontraba la Cantina. Cierto día de julio, acudieron tres hombres a palacio e hicieron pesquisas para averiguar cuál era la silla de manos de Nicolasa Cantín. Cuando esto llegó a oídos de la dama francesa, solicitó permiso a la reina para pernoctar en palacio y dio orden de que por la noche llevasen la silla a su casa. En un punto del recorrido, los tres hombres "llegaron y abrieron las cortinas y, viendo no iba, de rabia la hicieron pedazos y descalabraron a un mozo" 82 .

El 14 de julio de 1685, cuatro días después de que se hubiera tomado declaración a Margarita Lautier y su esposo, Francisco Bravo de Sobremonte acudió a la casa del Conde de Oropesa en torno a las once de la noche, tras haber realizado su ronda habitual por las calles de Madrid. El Conde de Oropesa le ordenó entonces prender y asegurar de manera inmediata las personas de Nicolasa Cantín y Juan de Viremont. Para ello mandó que a los alguaciles que habían hecho la ronda con Bravo de Sobremonte se sumasen el alcalde de corte Antonio de Argüelles y sus alguaciles, así como Luis de Soto, caballero del Marqués de los Vélez, y Luis Ferreira, teniente de maestre de campo general, al que acompañaron tres alféreces reformados ${ }^{83}$. Cuando los ministros de justicia llamaron a la puerta de la casa del matrimonio francés y les abrió la

79 BNE, Ms. $18755 / 19$, f. 2Ar.

80 ASVE, Senato, Dispacci degli ambasciatori, Spagna, C. ${ }^{\text {a }}$ 121, 12 de julio de 1685.

81 BNE, Ms. 18755/19, f. 4Av.

82 BNE, Ms. 11017, f. 222r.

83 La participación del Marqués de los Vélez en este proceso a través del mencionado Luis de Soto se debe a su condición de caballerizo mayor de la reina María Luisa de Orleans, cuyo nombramiento se efectuó por real decreto el 1 de noviembre de 1683, tras la destitución del Duque de Osuna (AGP, Personal, C. ${ }^{a}$ 1084/19). 
puerta un criado, encontraron a Viremont con una pistola cebada y un espadín bajo el brazo, con los que pretendía defenderse en caso de que las turbas callejeras atacaran su hogar. Viremont, sin embargo, no opuso ninguna resistencia y tanto él como su esposa fueron conducidos en un coche a la residencia de Francisco de Rozas, caballero de la Orden de Alcántara, situada enfrente de la escalera de San Basilio, en la calle de Valverde. Una vez allí, fueron encerrados en el subsuelo en dos piezas separadas ${ }^{84}$.

Al día siguiente, el domingo 15 de julio, Francisco Bravo de Sobremonte acudió a la calle Valverde a interrogar a la Cantina ${ }^{85}$. Cuando el juez conservador de los franceses le preguntó por qué creía que la habían detenido, la dama contestó que no lo sabía, pero que presumía que era "porque se ha dicho que [...] quería dar veneno al rey nuestro señor, estando como está inocente de tal maldad" ${ }^{" 86}$. Se le preguntó entonces qué relación tenía con Margarita Lautier, a lo que respondió que cuando la clavecinista estuvo empleada en palacio "no se trataban, porque la Lotier decía a la reina muchos males de ella" ${ }^{87}$. Cantín pasó entonces a acusar a la clavecinista y su esposo de intentar asesinar a su marido y a ella misma, señalando que tanto María Luisa de Orleans como el conde de Oropesa estaban informados de ello. Bravo de Sobremonte, que entendía dicho episodio como un asunto de importancia secundaria, preguntó a Nicolasa Cantín si había suministrado bebidas y píldoras a la reina. Esta contestó que "solo en una ocasión, delante del rey, en una gota de vino dio a la reina un poco de triaca para el dolor de estómago y en otra ocasión le dio otro poco de triaca para lo mismo" ${ }^{88}$. Cuando el juez le interrogó acerca del paradero de la triaca, la antigua nodriza de María Luisa de Orleans fue incapaz de construir un testimonio coherente; primeramente señaló que estaba "en casa en un pucherico", a continuación indicó que "no está en su casa sino en un cofre del retrete de la reina", más adelante aseguró que "no se acuerda su pucherillo de triaca adónde fijamente esté en palacio, porque ha días no le ha visto ni usa este remedio" y finalmente afirmó que "no sabe de fijo si era triaca lo que dio a la reina o otra medicina que tenía [...] y se llamaba orbiata y sirve de lo mismo que la triaca y que estaba en algún cofre de retrete, si hay algo de ello" ${ }^{89}$. Aquello dio motivos al juez para comenzar a sospechar de la acusada.

Ese mismo día Bravo de Sobremonte pasó a interrogar a Juan de Viremont. Tras comunicarle los cargos de espionaje que le imputaba Pedro Levillane, aseguró que Luis XIV en ningún momento lo había indultado. Durante toda su declaración, el normando insistió en que todas las acusaciones que se planteaban contra él y su esposa carecían de fundamento. Según sostenía, eran fruto perverso de la malicia de Levillane y Lautier, en cuyos odios había incurrido inopinadamente. Por último, acusó al antiguo caballerizo de pretender matarlo.

El día 16 de julio, Francisco Bravo de Sobremonte procedió a tomar declaración a María Martínez, casera de Margarita Lautier y su esposo, que dio cuenta de las visitas del criado de espada de Mariana de Aguirre, Isidro Espinosa de los Monteros, al cual

84 BNE, Ms. 18755/19, ff. 4Br-v.

85 Ibidem, f. 5Ar.

86 Ibidem, f. 5Av.

87 Ibidem, f. 5Br.

88 Ibidem, f. 6Av

89 Ibidem, ff. 6Av-6Br. 
el licenciado interrogó aquel mismo día. Este afirmó cumplir órdenes de Mariana de Aguirre y aseguró no saber nada del caso ni de lo que trataron su señora y Pedro Levillane en sus coloquios. La jornada de interrogatorios concluyó con la segunda declaración de Pedro Levillane, que negó haber pretendido acabar con la vida de Viremont.

Al día siguiente, 17 de julio, Bravo de Sobremonte tomó segunda declaración a Margarita Lautier. Cuando se le preguntó si existía algún otro testigo de los brebajes y píldoras de la Cantina, la clavecinista respondió que esta se cuidaba mucho de que en aquellas ocasiones no hubiera nadie a su alrededor. Lautier también restó importancia a la denuncia de Viremont contra su esposo y aseguró que los acusados habían ideado aquel embuste para escamotear su propia culpa. Ese mismo día pasó Bravo de Sobremonte a interrogar a Pedro Burlé, criado de Juan de Viremont, natural de Lorena, que se encontraba detenido en casa del alguacil Nicolás de Uruñuela. Por no conocer la lengua castellana, se nombró como intérprete al alférez reformado Antonio Varela. A Pedro Burlé se le interrogó principalmente acerca de la acusación de espionaje de Viremont, sobre lo cual Burlé juró no saber nada. Cuando se le pidió que citara los nombres de los amigos con los que su amo trataba más familiarmente, mencionó a "Monsiur Chavarría y Monsiur Purdón y Monsiur Fornó"".

El 18 de julio, Francisco Bravo de Sobremonte comenzó la jornada tomando declaración a dos de los amigos de Juan de Viremont mencionados en el auto. En primer lugar interrogó a Juan de Chavarría, cerero mayor de la reina madre, de treinta y ocho años de edad, galán de la bufetera Susana Duperroy, como se ha dicho. Chavarría confesó ser estrecho amigo de Juan de Viremont y confirmó que el Cristianísimo había perdonado al militar normando, pero aseguró que este nunca se entrevistó con el rey, sino que el indulto le fue comunicado a través de la esposa del Duque de Orleans. A continuación, el juez interrogó en su residencia a Juan Claudio Purdón, capitán de caballos, de treinta y siete años de edad ${ }^{91}$. Este dio cuenta de una conversación que mantuvo con Pedro Levillane cinco días antes de su partida a Cuenca, es decir, el lunes 18 de junio de 1685. Aquel día Levillane pasó a visitarlo a su posada y, tras quejarse amargamente de Viremont, juró que habría de matarlo junto con Nicolasa Cantín.

A continuación, Francisco Bravo de Sobremonte pasó a interrogar a las dos vecinas en cuya casa se había cobijado por miedo Margarita Lautier el día 20 de junio. Estas eran Úrsula González, viuda de Domingo Magadán, que fue oficial de la sala de alcaldes de corte, y María de la Mata, viuda de Tomás Romero, oficial en la misma sala. Ambas vinieron a confirmar la declaración de la clavecinista.

Acabados los interrogatorios, aquel mismo día 18 de julio, Bravo de Sobremonte acudió a la residencia del Conde de Oropesa, que le informó de que la Junta había acordado que se inspeccionara un cofrecillo que el alcalde de corte Antonio de Argüelles había prendido entre los bienes de Nicolasa Cantín y que contenía diversos botes

90 Ibidem, f. $12 \mathrm{Br}$.

91 A pesar de que en el auto su apellido ha sufrido una metátesis, parece claro que este capitán de caballos ha de ser Juan Claudio Prudhom, natural del Condado de Borgoña, que obtuvo el empleo de consejero y tesorero de la Orden del Toysón de Oro por decreto de Carlos II del 7 de octubre de 1683. Véase PINEDO Y SALAZAR, J. de: Historia de la insigne orden del Toysón de Oro, dedicada al rey nuestro señor, jefe soberano y gran maestre de ella, Madrid, Imprenta real, 1787, t. II, pp. 588-589. 
y frascos. En cumplimiento de esta orden, Bravo de Sobremonte convocó en su posada a las cuatro de la tarde de ese mismo día a Juan de Chavarría - que casualmente compartía nombre con uno de los interrogados-y Miguel de Alba, protomédicos reales, y a Diego Martínez Pedernoso, boticario mayor de Carlos II. En la inspección del cofre, se identificaron numerosas sustancias cosméticas y medicinales, como polvos de olor, pastillas de azúcar, agua de la reina de Hungría, polvo de víboras, confección de jacintos, triaca magna y quintaesencia de clavos $^{92}$. Aunque no se halló ninguna píldora sospechosa, los peritos aseguraron que algunas de las sustancias que contenían aquellos botes, en particular la triaca, si se administraban sin tiento, podrían hacer malparir a una mujer. A falta de un testigo que pudiese corroborar la denuncia de Margarita Lautier, el caso contra la Cantina contaba ya con una prueba indiciaria.

A medida que se instruía el proceso y se difundían los más rocambolescos rumores en la corte, el Marqués de Feuquières veía la situación con honda preocupación; imaginaba el embajador francés, embaucado por las novelescas informaciones que le suministraba el Duque de Camiña, que las denuncias de Margarita Lautier, diseñadas por el Conde de Mansfeldt, tenían como objetivo permitir a la reina madre procesar y condenar a María Luisa de Orleans, haciendo accesible, una vez disuelto el matrimonio real, el trono español a una princesa austríaca. Suponía también Feuquières que los conjurados tramaban dar muerte a la Cantina mediante venenos olfativos, flores tóxicas o guantes envenenados y que amenazaban al rey con derribarlo del trono si se obstinaba en amparar a la reina. Por último, como queda registrado en su correspondencia, el embajador contemplaba también la posibilidad de que, una vez apartada María Luisa de Orleans, el Conde de Oropesa tramase desposar a Carlos II con la infanta de Portugal; estos esponsales favorecerían la ascensión de Oropesa al codiciado trono portugués ${ }^{93}$.

El martes 19 de julio, prosiguió el licenciado Bravo de Sobremonte con la instrucción del proceso, interrogando al capitán de caballos Arnesto Gorci, de treinta y un años de edad. Este confirmó que Pedro Levillane le había confesado en varias ocasiones que quería matar a Viremont, aunque Gorci lo entendió como un mero desahogo, ya que tenía a Levillane "por un pobrete"

Fue entonces cuando la agitación popular, alentada por los próceres de la facción austracista en la corte, devino en violento motín. Los amotinados, reunidos en bandas, saqueaban los comercios regentados por franceses y arrojaban piedras contra todo aquel que pudiera parecer de aquella nación ${ }^{95}$. La flagrante miseria que padecía la población, la animosidad natural contra los ministros de justicia y la debilidad del gobierno hacían temer, en palabras del embajador veneciano, una revolución gene$\mathrm{ral}^{96}$.

92 BNE, Ms. 18755/19, f. 15Br. Para una descripción de algunos de los productos aquí mencionados, que no podemos apurar por razones de espacio, véase el detallado estudio de Oliván, L. y Pilo, R.: "Recetario en busca de dueño: perfumería, medicina y confitería en la casa del VII Duque de Montalto", Cuadernos de Historia Moderna, 37 (2012), pp. 103-125.

93 Véase MAURA, op. cit. (nota 1, s.a.), pp. 154-155, y MAQUART, op. cit. (nota 9), p. 64.

94 BNE, Ms. 18755/19, f. 16Av.

95 AMAE, Correspondance Politique, Espagne, t. LXIX, ff. 235r-v.

96 El diplomático se expresaba en los términos siguientes: "Per la miseria di questo popolo, per l'animosità naturale contro li Ministri della Giusticia et per la nota debolezza del Goberno poteva passare ad'una rivolutio- 
El miércoles 20 de julio tuvo lugar el interrogatorio de Mariana de Aguirre, habido en la casa de Bernabé de Otalora Guevara, miembro del Consejo de Castilla, situada en la calle del Caballero de Gracia. En su declaración, Aguirre puso todo su empeño en defender su persona y la de Nicolasa Cantín, asegurando que ninguna de ellas se benefició nunca del favor de la reina María Luisa. No perdió tampoco la oportunidad de atacar a Margarita Lautier, a la que tachó de "grandísima loca y sin alma" concluir el interrogatorio de Mariana de Aguirre, el licenciado Bravo de Sobremonte entregó las nuevas declaraciones al Conde de Oropesa.

El día 22 de julio, la Junta ordenó el traslado de la Cantina a la cárcel de la corte, adonde fue conducida por Francisco Bravo de Sobremonte, con asistencia de tres alguaciles, entre las nueve y las diez de la noche. Una vez en la sala de apelaciones, se sometió a la dama a un nuevo interrogatorio. Se le preguntó si había abusado de las honras y gracias de la reina, si había suministrado a esta bebidas y píldoras abortivas, si estaba involucrado en el asunto Juan de Viremont y si contaba con algún otro cómplice. La Cantina respondió que solo en contadas ocasiones dio alguna bebida o triaca a la reina para el dolor de estómago y que todo lo demás era falso testimonio levantado por Margarita Lautier y Pedro Levillane.

Aquello representaba una pésima noticia para el Conde de Oropesa, que sabía que su victoria sobre el partido francés en la corte solo sería absoluta si arrancaba a la Cantina una confesión de culpabilidad. Por ello, se dispuso que la dueña de retrete fuera llevada a tormento. En cumplimiento de esta orden, aquella misma noche, a la una de la mañana, Bravo de Sobremonte comunicó a la prisionera la decisión de la Junta y le pidió que confesara sus delitos. Esta contestó que en sus declaraciones constaba toda la verdad. El juez obtuvo la misma respuesta cuando le solicitó por segunda vez que reconociese su culpabilidad. Una vez conducida a la sala de la torre de la cárcel donde se encontraba el potro de tortura, se le hizo un tercer requerimiento, pero la dama francesa juró de nuevo que era inocente. Bravo de Sobremonte ordenó entonces que se procediera al suplicio. El cirujano de la cárcel, Juan de Isla, tras examinar a la detenida, declaró que no tenía lesión que impidiese la ejecución del tormento. Cuando el verdugo Alonso de Alcalá ató a la dama en el potro, el juez la apremió a confesar los delitos, pero ella respondió que todo cuanto había dicho era la verdad. El tormento se inició a las dos y media de la noche, consistente en cuatro ligaduras, cuatro vueltas, un garrote en el brazo derecho y un trampazo en el pie izquierdo ${ }^{98}$. Durante todo el proceso, Nicolasa Cantín, entre gritos y alaridos, proclamó una y otra vez su inocencia. El tormento concluyó a las cuatro menos cuarto de la madrugada. Pasaron entonces a la prisionera a la cama que estaba prevenida en una celda contigua y el juez dio orden de que la curasen y asistiesen.

La firmeza de la antigua nodriza en el potro, que permaneció inconfesa a pesar de lo severo de los tormentos, persuadió a Francisco Bravo de Sobremonte y, a través de este, al Conde de Oropesa de que la inculpada era inocente de los delitos que se le imputaban.

ne generale" (ASVE, Senato, Dispacci degli ambasciatori, Spagna, C. ${ }^{\text {12 } 121,26}$ de julio de 1685).

97 BNE, Ms. $18755 / 19$, f. $17 \mathrm{Ar}$.

98 Ibidem, f. 22 Av. 


\section{LA SENTENCIA}

El día 24 de julio de 1685, casi una semana después del inicio de la revuelta popular, se publicó finalmente un bando que prohibía severamente el maltrato a extranjeros. Gracias a esta medida, los alborotos menguaron considerablemente ${ }^{99}$.

Ese mismo día los miembros de la Junta procedieron a examinar el auto del proceso. El secretismo que distinguió el proceso contra la Cantina nos impide conocer el resultado de la deliberación de la Junta, aunque se rumoreaba que sus miembros, aconsejados por el Conde de Oropesa, habían resuelto condenar a muerte a la Cantina ${ }^{100}$. Fuera como fuere, una vez alcanzado el veredicto, la Junta propuso pasar a consultar al rey y reunirse de nuevo el 27 de julio para ejecutar lo que este hubiera dispuesto. Esta es la última diligencia que consta en el auto instruido por Francisco Bravo de Sobremonte.

Carlos II, tras sopesar las implicaciones domésticas y políticas del caso, no siguió adelante con la idea de la ejecución; por un lado, temía incurrir en la temible cólera de María Luisa de Orleans, habida cuenta de que la Cantina parecía inocente de los cargos de envenenamiento que se le imputaban. Por otro lado, en el marco de la frágil tregua de Ratisbona, le inquietaba sobremanera la acumulación de tropas francesas en la frontera con Navarra y Cataluña. Recordando tal vez la notable calma que siguió a la partida de la servidumbre francesa de la reina en 1681, el soberano resolvió desterrar a Cantina y sus secuaces, así como a todos los nuevos siervos franceses que habían sido empleados en los últimos años, sentencia esta en la que, como apuntaba en su correspondencia Sebastiano Foscarini, prevaleció el "consiglio politico" sobre el "decretto giuridico" 101.

En previsión de las dificultades que opondría la reina María Luisa una vez enterada del decreto, Carlos II decidió obrar con prudencia. Así, antes de la promulgación, el soberano ordenó que el sábado 28 de julio, al abrigo de la noche, fuera prendida y asegurada la última confidente de la reina que permanecía entonces en palacio, Susana Duperroy, sobrina de la Cantina, hasta que fuese expulsada con el resto de franceses. Así narra el episodio Rodrigo Fernández Zorrilla ${ }^{102}$ :

Las novedades que hay por acá son haber ido el sábado a las once y media de la noche un alcalde con una orden del rey a la señora camarera para que le entregase a Susana, una francesa sobrina de la Cantina, que no sabía yo lo era, de la cámara. Entregósele dando ella muchas voces y gritos y llevole a casa de don Antonio Ortiz, marido de la primera sobrina de la Cantina, secretario hoy de Indias. Él sintió mucho se la llevasen, pero por orden del rey la recibió.

A la mañana siguiente, María Luisa de Orleans llamó a Susana Duperroy para vestirse y no la pudo encontrar. Carlos II notificó entonces a su esposa que era su voluntad desterrar no solo a la Cantina y Viremont, como intuía la reina María Luisa, sino

\footnotetext{
99 AMAE, Correspondance Politique, Espagne, t. LXIX, f. 240v.

100 ASVE, Senato, Dispacci degli ambasciatori, Spagna, C. ${ }^{a}$ 123, 9 agosto de 1685.

101 Ibidem.

102 AHN, Nobleza, Osuna, CT. 47, D. 9, 1 de agosto de 1685.
} 
a todos los demás franceses, incluida su querida bufetera. De la reacción de la reina al verse privada del último amparo de su cámara da cuenta el autor de la mencionada carta anónima conservada en la Biblioteca Nacional, en los siguientes términos ${ }^{103}$ :

Empezó a hacer tales bramuras que no es fácil ponderarlas. Entre ellas fue una quererse echar por una ventana, lo cual embarazó la señora doña Francisca Enríquez ${ }^{104}$. Otra fue pedir unas tijeras para cortarse el pelo. Otra, decir que trajesen postas para irse a Francia. Otra, no querer oír misa y la última, encerrarse en su cuarto hasta las nueve de la noche, que el rey llamó al Presidente [de Castilla, i.e., el Conde de Oropesa] y le mandó que hiciese volver a Susana a palacio.

Con el fin de serenar a su esposa, el rey no solo permitió que Susana Duperroy permaneciese a su servicio, sino también un cocinero y un boticario. Quedó al lado de la reina también su confesor, un jesuita francés de conocida probidad y sencillez, por lo que nunca se pensó en desterrarlo ${ }^{105}$. Aquel paliativo molestó sobremanera al Conde de Oropesa. Tanto fue así que amenazó con dejar el gobierno, exclamando que el rey "ni con Dios ni con el mundo cumple si no hace justicia" ${ }^{106}$. Con todo, a la postre hubo de resignarse y aceptar la presencia de aquel reducido grupúsculo de franceses en la casa de la reina.

Una vez pasado aquel domingo, el lunes 30 de julio de 1685 se promulgó el real decreto por el que se expulsaba a Juan de Viremont, Nicolasa Cantín y Juan de Chavarría, así como a toda la servidumbre francesa de palacio ${ }^{107}$. Según cuenta Sebastiano Foscarini, en cuanto el Marqués de Feuquières tuvo noticia del decreto, aplaudió en privado el destierro de la Cantina y su camarilla, pues se veía por fin libre de embarazos para ejecutar adecuadamente las tareas de su misión diplomática, aconsejando, guiando y asistiendo a la sobrina de Luis XIV. No obstante, públicamente dio grandes muestras de indignación al entender injusta la resolución del caso, en el que se habían dado por ciertas las animosas denuncias de Pedro Levillane, en perjuicio del buen nombre de la reina ${ }^{108}$. Así, el mismo día de la promulgación del decreto, el anciano embajador envió un pliego a su comisario en la corte, Don Pedro de Aragón, en el que reclamaba se le enviase una copia de la sentencia. Tres días más tarde, se le despachó esta sobria respuesta ${ }^{109}$ :

103 BNE, Ms. 11017, f. 222r. El embajador de Venecia comenta en su relato del lance que el confesor de la reina fue llamado con toda urgencia para que sosegase su ánimo, pero se vio incapaz de hacerlo. María Luisa de Orleans, ahogada en llanto, repetía una y otra vez que Viremont y su esposa eran inocentes y que Levillane tenía que ser castigado (ASVE, Senato, Dispacci degli ambasciatori, Spagna, C. ${ }^{a} 123,9$ de agosto de 1685).

104 Se trata de Francisca Enríquez de Velasco, hija de los marqueses de Alcañices y sobrina del Condestable de Castilla. Había sido nombrada dama tocadora de la reina María Luisa en el real decreto del 19 de agosto de 1679 (AGP, Personal, C. . . 2620/11). En 1683 fue promovida al puesto de dama copera de la reina (AMAE, Correspondance Politique, Espagne, t. LXVIII, f. 475r).

105 ASVE, Senato, Dispacci degli ambasciatori, Spagna, C. ${ }^{\text {a }}$ 123, 9 de agosto de 1685.

106 BNE, Ms. 11017, f. 222v.

107 Ibidem, ff. 222r-v.

108 ASVE, Senato, Dispacci degli ambasciatori, Spagna, C. ${ }^{a}$ 123, 9 de agosto de 1685.

109 BNE, Ms. 12953/43. 
Habiendo visto el rey mi señor el papel que V.E. me ha escrito el 30 del pasado de que con motivo de inviarse a Francia los criados de la Reina nuestra señora, dice V.E. que respecto de las acusaciones que ha habido entre ellos y han causado en Madrid la comoción popular que se sabe, deseando V.E. informar con certidumbre al rey su amo de los motivos de lo resuelto, sea hacia absolverlos o condenarlos, pide se le brinden copias de las sentencias para que en Francia se sepa si están culpados o inocentes en la calumnia, pues en este segundo caso supone V.E. que pudieran volver a entrar algunos de ellos en el servicio de aquella real casa como estaban antes de venir a España, ha resuelto el rey mi señor responda a V.E. que la deliberación de inviar a unos y despedir a otros ha sido motivada de los inconvenientes que entre ellos mismos han nacido y que de los que se encaminan a la frontera solo Don Juan de Videmont y su mujer Francisca Cantín han merecido el real desagrado de S.M., de que informará al Rey Cristianísimo el Barón del Val, su enviado, sobre el presupuesto de que los criados de la reina nuestra señora ha querido S.M. se traten con más atención de la que merecían algunos y que no se publique la resolución de S.M. en esta parte como sentencias en justicia, sino como deliberaciones en gobierno, de que participo a V.E.

Madrid y 2 de agosto de 1685.

En cumplimiento de la orden real, se procedió a reunir caudales en las exangües arcas del reino para conceder una ayuda de costa de mil pistolas de oro a cada uno de los súbditos franceses expulsados. Los primeros de ellos que abandonaron Madrid lo hicieron el día 1 de agosto, al caer la noche, para evitar posibles altercados. La segunda partida dejó la villa la noche del día siguiente ${ }^{110}$. Debido a las heridas que se le infligieron en el tormento, Nicolasa Cantín, acompañada de su marido, hubo de partir algunos días más tarde y, en todo caso, antes del 8 de agosto ${ }^{111}$. Según apunta el Marqués de Dangeau en sus memorias, la antigua nodriza llegó a Bayona el sábado 18 de agosto de $1685^{112}$.

Para desconsuelo de la reina María Luisa, Margarita Lautier y Pedro Levillane fueron recompensados por los servicios prestados a la corona; se les concedió una ayuda de costa de seis mil reales de a ocho y una pensión anual de mil reales de a ocho y se ordenó que marchasen a vivir a las Canarias ${ }^{113}$. Según se rumoreaba, con este traslado se pretendía evitar que los agentes de Luis XIV, una vez enterados del caso, acabaran con la vida del matrimonio ${ }^{114}$.

El decreto promulgado el 30 de julio también establecía que Mariana de Aguirre y su marido Bernardino de Valdés fueran desterrados a varias leguas de la corte durante veinte años y que el segundo se viera privado de su plaza en el Consejo de Indias y no pudiera ejercer cargo público alguno en un periodo de ocho años ${ }^{115}$.

110 AMAE, Correspondance Politique, Espagne, t. LXIX, ff. 241v y 244r.

111 AHN, Nobleza, Osuna, CT. 47, D. 10, 8 de agosto de 1685.

112 Dangeau, op. cit. (nota 36), t. I, p. 136.

113 BNE, Ms. 11017, f. 222v.

114 AHN, Nobleza, Osuna, CT. 47, D. 10, 8 de agosto de 1685.

115 AMAE, Correspondance Politique, Espagne, t. LXIX, f. 241v. Los testimonios no coinciden al apuntar en cuántas leguas de la corte consistía el destierro; Heemskerk y el autor anónimo de la carta redactada en julio de 1685 consignan catorce leguas (BNE, Ms. 11017, f. 222v), mientras que señalan treinta leguas Sebastiano Foscarini (ASVE, Senato, Dispacci degli ambasciatori, Spagna, C. ${ }^{a} 121,9$ de agosto de 1685) y Rodrigo 
La expulsión de los franceses de la corte, si bien aplacó la ira de los amotinados, no disolvió su indignación; enardecida por los imperiosos avances de Luis XIV en los estados de Flandes, la población madrileña pedía penas mayores para los acusados franceses. Según apuntaba el embajador Heemskerk, en todos los mentideros de la villa se comentaba que había llegado el momento de dejar de hostigar a los ciudadanos extranjeros y lapidar en su lugar a jueces y cortesanos ${ }^{116}$. El odio de la multitud contra María Luisa de Orleans, a la que muchos tenían por colaboradora en los planes de la Cantina, seguía siendo implacable. En ese estado de cosas, a finales del mes de agosto de 1685, se divulgó una noticia, que relataba del modo siguiente el Duque de Montalto en un despacho al embajador español en Londres ${ }^{117}$ :

En este correo tengo muy pocas novedades que suministrar a V.E. de esta corte, porque no las hay desde que faltó el material ruidoso de los venenos Cantinos, de cuyo éxito de causa di cuenta a V.E. La reina parece se halla más aconohortada de la falta de sus franceses y tengo por cierto que sin ellos ha de vivir con más sosiego y gusto, pues esta peste de gente no creo que trabajaba en otra cosa que en la desconfiarla de los españoles. Ha muchos días y se pueden contar meses que no sale fuera a ninguna función ni paseo y cualquiera que se lo aconseja obra con prudencia, particularmente los días de la bulla de las prisiones de aquella gente, porque el populacho, que no conoce de respetos, pudiera haberle perdido con voces descompuestas. También es verdad que quieren decir tiene algunas sospechas de preñada, pero de esto no se hace mucha finca, porque en diferentes ocasiones ha tenido faltas de dos meses y más y se ha desengañado y reconocido ser retención de ellos.

Como bien recelaba el Duque de Montalto, María Luisa de Orleans no llegó a producir un heredero en aquella o en alguna otra ocasión, pero la noticia le devolvió, siquiera temporalmente, su perdida popularidad.

\section{EPÍLOGO}

Los protagonistas de uno de los casos más polémicos del reinado de Carlos II tuvieron destinos muy diferentes.

Nicolasa Cantín, recibida como una heroína por el pueblo francés, fue notablemente recompensada. En diciembre de 1685, su antiguo patrono, el Duque de Orleans, le concedió un aposento en el Palais Royal. Además, puso a su disposición los mejores tratamientos médicos disponibles para que pudiera restablecerse de sus lesiones ${ }^{118}$. Cuando el 12 de febrero de 1689 María Luisa de Orleans falleció, a resultas de una caída de caballo o, como el Marqués de Feuquières sospechaba, de un envenenamiento, se procedió a la lectura de su testamento, en el que la reina legaba 4000 pistolas de

\footnotetext{
Fernández Zorrilla (AHN, Nobleza, Osuna, CT. 47, D. 9, 1 de agosto de 1685). Este último, por cierto, era vecino de Mariana de Aguirre y Bernardino de Valdés.

116 AMAE, Correspondance Politique, Espagne, t. LXIX, f. 242r.

117 Montalto, op. cit. (nota 5), p. 326, 30 de agosto de 1685.

118 Así lo detalla en su gaceta el religioso agustino Léonard, citado por Morel-Fatio en las notas a su edición de VILLARS, op. cit. (nota 22), p. 322.
} 
oro a su antigua nodriza ${ }^{119}$. No obstante, ya fuera por la pésima situación financiera por la que atravesaba España o por el aborrecimiento que aún inspiraba en la corte, lo cierto es que Nicolasa Cantín no llegó a recibir dinero alguno. En 1703, escribió un memorial al consejo real desde su retiro en Francia, en que se solicitaba el pago de las pistolas prometidas, pero su petición le fue denegada ${ }^{120}$.

Su sobrina Susana Duperroy tuvo mejor fortuna; antes de fallecer María Luisa de Orleans, esta dejó dispuesto que a su bufetera se le entregase 3000 pistolas de oro junto con una valiosa joya, como se cumplió, y se la desposase con un caballero llamado Don Juan Tomás de Iriarte, al que se concedería la Secretaría de Descargos ${ }^{121}$. La boda de Duperroy e Iriarte se celebró el día 27 de abril de 1689 en el Alcázar Real ${ }^{122}$. Al parecer, una vez fallecido Iriarte, su viuda se desposó con Don Felipe Tomás Remírez y Calderón, caballero de Santiago y caballerizo real, que falleció sin descendencia en $1706^{123}$. Ignoro la fecha de fallecimiento de Susana Duperroy.

A Mariana de Aguirre también le sonrió la fortuna; como hemos apuntado, la dama tenía pena de destierro de la corte durante veinte años. Sin embargo, no permaneció mucho tiempo fuera de Madrid; la reina María Luisa logró que en abril de 1686 Mariana de Aguirre fuese indultada. Así relata el episodio el Duque de Montalto ${ }^{124}$ :

Ya sabe V.E. que doña Mariana de Aguirre fue desterrada con su marido por los cuentos de la Cantín. Pues de algunos días a esta parte ha sido tal la diligencia de la reina en orden a que vuelva que llamó al Conde de Oropesa para que aconsejase al rey viniese en ello y aunque el Conde, en mi entender, no deja de contemporizar y vivir con todos [...], en esta ocasión se ha portado con gran entereza respondiéndola que no podía venir en lo que Su Majestad gustaba porque había sido de contrario dictamen y representado al rey los grandes motivos que había habido para que esta mujer hubiese sido desterrada [...], con que la reina lo despidió con gran mesura y ceño y pasó a gritar a su marido y a poner pies en pared en que había de venir la Aguirre. [...] Repitió los oficios tan fuertes y tan lamentables que, congojado con ellos, hubo de rendirse a venir en lo que la reina deseaba. $\mathrm{Y}$ con efecto viene ya a la corte esta mujer, que será peor que todos los diablos juntos y peor que la Cantín.

119 Maura, op. cit. (nota 1, 1990), p. 344.

120 Real Academia de la Historia, Colección Pellicer, t. XXXII, ff. 266v-267r

121 Piga, A. y CARro, S.: Informes sobre la causa de la muerte de la reina María Luisa de Orleans, Madrid, Cosano, 1948, p. 49.

122 Juan Tomás de Iriarte y Elizalde, caballero de la orden de Santiago desde febrero de 1684, era natural de Pamplona (AHM, Órdenes Militares, Caballeros de Santiago, Exp. 4123). El 22 de enero de 1690 este matrimonio hizo la ceremonia nupcial de la velación en el oratorio de la casa de Antonio Ortiz, marido, como se ha dicho, de la segunda sobrina de Nicolasa Cantín (Fernández García, M.: Parroquia madrileña de San Sebastián; algunos personajes de su archivo, Madrid, Caparrós, 1995, p. 544).

123 Mayoralgo y Lodo, J. M.: "Necrologio nobiliario madrileño del siglo XVIII (1701-1808)", Hidalguía, 327 (2008), pp. 149-202 (p. 177). Véanse los datos biográficos acerca de Remírez y Calderón en su expediente para la concesión del título de caballero de la Orden de Santiago (AHN, Órdenes militares, Caballeros de Santiago, Exp. 6848).

124 Montalto, op. cit. (nota 5), pp. 347-348, 10 de abril de 1686. 
El marido de Mariana de Aguirre, Bernardino de Valdés, que fue desterrado con ella, había logrado su rehabilitación en el Consejo de Indias mucho antes, probablemente en septiembre de $1685^{125}$.

Los instigadores del proceso, Pedro Levillane y Margarita Lautier vivieron durante muchos años en las Islas Canarias, disfrutando de la renta anual concedida a aquel por la corona. En 1698 falleció Levillane, a la temprana edad de treinta y ocho años. Ese mismo año, su viuda presentó un memorial para que se le asignara una ración con la que poder vivir, por hallarse en gran necesidad. Sin embargo, su petición fue rechazada ${ }^{126}$. Se ignora su fecha de fallecimiento. 